\title{
Multichannel and Super-flexible SiZrOC Ultrafine Fibers for High Temperature Thermal Insulation
}

\author{
Xiaoshan Zhang \\ National University of Defense Technology \\ Qiong Tian \\ National University of Defense Technology \\ Bing Wang \\ National University of Defense Technology \\ Nan Wu \\ National University of Defense Technology \\ Cheng Han \\ National University of Defense Technology \\ Xin Long \\ National University of Defense Technology \\ yingde wang ( $\nabla$ wangyingde@nudt.edu.cn ) \\ National University of Defense Technology https://orcid.org/0000-0001-8615-194X
}

\section{Research Article}

Keywords: Multichannel structure, SiZrOC, Flexibility, High-temperature, Thermal insulation

Posted Date: March 8th, 2021

DOl: https://doi.org/10.21203/rs.3.rs-284149/v1

License: (c) (i) This work is licensed under a Creative Commons Attribution 4.0 International License.

Read Full License 


\title{
Multichannel and super-flexible SiZrOC ultrafine fibers for high temperature thermal insulation
}

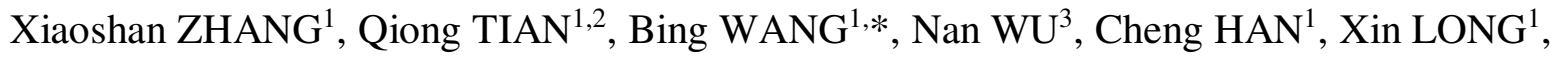 \\ Yingde $\mathrm{WANG}^{1, *}$ \\ ${ }^{1}$ Science and Technology on Advanced Ceramic Fiber and Composites Laboratory, ${ }^{2}$ Jiuquan \\ Satellite Launch Center, Jiuquan 735400, China, ${ }^{3}$ Department of Material Science and \\ Engineering, College of Aerospace Science and Engineering, National University of Defense \\ Technology, Changsha 410073, China
}

Keywords: Multichannel structure, SiZrOC, Flexibility, High-temperature, Thermal insulation

Abstract: Light but robust porous ceramic fibers with combined properties of super flexibility, excellent thermal stability and thermal insulation performance are attractive for use in extreme conditions, especially in the field of aerospace. However, the practical application of traditional porous ceramic fibers are usually limited by their brittle nature and poor mechanical properties. Herein, we designed a multichannel SiZrOC ultrafine fiber (MSUF) composed of $\mathrm{ZrO}_{2}, \mathrm{SiO}_{\mathrm{x}} \mathrm{C}_{\mathrm{y}}$ and free carbon phases by electrospinning technique. The resulting fibers exhibited integrated properties of excellent fire resistance, high temperature stability, thermal shock resistance and temperature-invariant flexibility. More importantly, the fancy multichannel structure and components of the fiber provides it with outstanding thermal insulation performance with low thermal conductivity $\left(0.041 \mathrm{~W} \mathrm{~m}^{-1} \cdot \mathrm{K}^{-1}\right.$ at $25^{\circ} \mathrm{C}$ and $0.141 \mathrm{~W} \mathrm{~m}^{-1} \cdot \mathrm{K}^{-1}$ at $\left.1000{ }^{\circ} \mathrm{C}\right)$. The successful 
fabrication of such flexible porous MSUFs may provide a new approach to design high performance thermal insulators for high temperature thermal insulation.

\section{Introduction}

In recent years, materials with robust mechanical properties, excellent thermal stability and low thermal conductivity are highly demanded in aerospace and deep space exploration fields, for personal and aircrafts protection [1-3]. While the aircrafts or vehicles reentry atmosphere at high speed, the temperature of the leading edge of the wing and other parts will increase rapidly up to $\sim 1000^{\circ} \mathrm{C}$ in a short time [1-2]. Thus, the thermal insulating materials applied to those aircrafts are always in service under extreme conditions, such as sharp temperature changes and long-period high temperature exposure $[4,5]$. In addition, these thermal insulating materials should not only be mechanical robust but also be light in order to conserve energy.

Ceramic fibers are considered as promising high temperature thermal insulators due to their outstanding fire resistance, high strength, as well as thermal and chemical resistance [6-9]. They can be used as both individual thermal insulators and reinforcements and opacifier of aerogel thermal insulators, which are both urgently demanded in the high temperature thermal insulation fields [9-12]. However, the thermal conductivities of the current ceramic fiber membranes are still high at high temperatures $\left(>0.20 \mathrm{~W} \mathrm{~m}{ }^{-1} \cdot \mathrm{K}^{-1}\right.$ at $\left.1000{ }^{\circ} \mathrm{C}\right)$, because of these kinds of fibers are transparent in the infrared (IR) region or have high intrinsic solid thermal conductivity [13-17]. Recently, we designed a multi-phase SiZrOC fiber contained both oxide and non-oxide phases, which exhibited excellent flexibility and thermal stability [9]. The unique component enhanced the phonon scattering and infrared shielding performance of the fibers, which endowed the fibers with a good thermal insulation performance at high temperatures $\left(0.169 \mathrm{~W} \mathrm{~m}^{-1} \cdot \mathrm{K}^{-1}\right.$ at $\left.1000{ }^{\circ} \mathrm{C}\right)$. 
However, the thermal insulation performance of the SiZrOC fibers needed to be further improved in order to meet the steep demands in aerospace field.

Recently, it has been found that constructing porous structure is an effective way to reduce the thermal conductivity of fibers [18-22]. On the one hand, the porous structure will lengthen the path of heat transfer and hinder the gaseous heat conduction, leading to a low solid and gas heat transfer $[18,19]$. On the other hand, the multiscale porous structure contributes to enhance multiple reflection-absorption of the IR radiation, which can decrease radiation heat transfer [16,20,21]. Moreover, the porous structure is beneficial to reduce the density of ceramic fiber membranes. Therefore, ceramic fibers with proper porosity and pore structure may endow thermal insulating materials with high thermal insulation performance and lightweight simultaneously.

On the basis of this, many kinds of porous ceramic fibers have been widely developed. Gbewonyo et al. [18] prepared porous carbon fibers with multi-scale (micro, submicro, and nano) porous structure delivered by electrospinning method. Compared with carbon fibers, the thermal conductivity of the porous carbon fibers with nanoscale structure decreased $98 \%$ to $0.15 \mathrm{~W} \mathrm{~m}^{-}$ ${ }^{1} \cdot \mathrm{K}^{-1}$ at ambient temperature. Wang et al. [19] reported $\mathrm{SiO}_{2}-\mathrm{TiO}_{2}$ and $\mathrm{SiO}_{2}-\mathrm{ZrO}_{2}$ fibers with highly porous structure. The numerous pores within the fiber could effectively reduce the solid heat transfer, confine the gaseous heat transfer and enhance the reflection of IR. Therefore, the $\mathrm{SiO}_{2}-\mathrm{TiO}_{2}$ and $\mathrm{SiO}_{2}-\mathrm{ZrO}_{2}$ porous fibers had great potential to be used in the thermal insulation fields. However, despite these advances, ceramic fibers with highly porous structure usually suffered from the poor mechanical properties, which was mainly due to the brittle nature of ceramics and numerous pore defects $[14,18,19]$. Therefore, it was still a long-standing challenge in designing porous structured ceramic fibers with both high flexibility and thermal insulation performance. 
Inspired by this, we designed a flexible multichannel SiZrOC ultrafine fiber (MSUF) fabricated via electrospinning technique by selecting polystyrene as the pore-forming template to regulate the pore structure in this work. The prepared MSUFs had multichannel structure and composed of $\mathrm{ZrO}_{2}, \mathrm{SiO}_{\mathrm{x}} \mathrm{C}_{\mathrm{y}}$ and free carbon phases, which exhibited excellent fire resistance, thermal shock resistance, thermal stability (up to $1400{ }^{\circ} \mathrm{C}$ in Ar) and temperature-invariant super flexibility (196 1000 $\left.{ }^{\circ} \mathrm{C}\right)$. Remarkably, the unique multichannel structure and components provided the MSUFs with high thermal insulation performance with low thermal conductivity $\left(0.041 \mathrm{~W} \mathrm{~m}^{-1} \cdot \mathrm{K}^{-}\right.$ ${ }^{1}$ at $25^{\circ} \mathrm{C}$ and $0.141 \mathrm{~W} \mathrm{~m}^{-1} \cdot \mathrm{K}^{-1}$ at $1000^{\circ} \mathrm{C}$ ). The developed MSUF membranes could be considered as promising high temperature thermal insulators under extreme conditions.

\section{Experimental}

\subsection{Materials}

Polysiloxane resin (PR) was purchased from Nanjing Kuncheng Chemical Co., Ltd., China. Polyvinyl pyrrolidone (PVP), Polystyrene (PS, $\mathrm{M}_{\mathrm{w}}=350000$ ), N,N-dimethylformamide (DMF), zirconium acetylacetonate $\left(\operatorname{Zr}(\mathrm{acac})_{4}, 98 \%\right)$ was provided by Aladdin Chemical Co., Shanghai, China. All chemicals were used as received without any purification.

\subsection{Preparation of the MSUF membranes}

The electrospinning solution (ES) was prepared by dissolving PR, PS, PVP and $\mathrm{Zr}(\mathrm{acac})_{4}$ in the DMF with stirring speed of $600 \mathrm{r} \cdot \mathrm{min}^{-1}$ at $40{ }^{\circ} \mathrm{C}$ for $6 \mathrm{~h}$. To tune the pore structure of the MSUFs, the various ES with PS contents from $2 \mathrm{wt} \%, 6 \mathrm{wt} \%, 10 \mathrm{wt} \%$ to $18 \mathrm{wt} \%$ was prepared for electrospinning, respectively. The corresponding ES with various PS was named as ES-2, ES-6, ES-10 and ES-18, respectively. The detail composition of the various ES was shown in Table S1. Then, the precursor fiber (PF) was electrospun on aluminum foil collector from various ES. The distance between the syringe and the collector was fixed at $15 \mathrm{~cm}$, and the voltage of $15 \mathrm{kV}$ was 
applied with a flow rate of $1 \mathrm{ml} \cdot \mathrm{h}^{-1}$. The corresponding PFs prepared by various ES were named as PF-2, PF-6, PF-10 and PF-18, respectively. The as-spun PFs were thermal cured in air at 310 ${ }^{\circ} \mathrm{C}$ for $2 \mathrm{~h}$ with heating rate of $1{ }^{\circ} \mathrm{C} \cdot \mathrm{min}^{-1}$. Then, the MSUFs were obtained by pyrolyzing the thermal cured PFs at $1200{ }^{\circ} \mathrm{C}$ for $1 \mathrm{~h}$ with heating rate of $5^{\circ} \mathrm{C} \cdot \mathrm{min}^{-1}$ under Ar atmosphere. The corresponding MSUF membranes were named as MSUF-2, MSUF-6, MSUF-10 and MSUF-18, respectively.

\subsection{Characterization}

The microscopic morphologies of the MSUFs were characterized by field-emission scanning electron microscopy (SEM, Hitachi S4800, Japan). The microstructure of the MSUFs was examined by a transmission electron microscopy (TEM, Titan G2 60-300, USA). The elemental composition was performed with an energy dispersive X-ray spectroscopy (EDS) equipped on the TEM. X-ray diffraction (XRD) pattern from the sample was collected in the range of $10^{\circ} \sim 80^{\circ}$ using an X-ray diffractometer (Bruker AXS D8, Germany) equipped with $\mathrm{Cu} \mathrm{K} \alpha$ radiation. X-ray photoelectron spectroscopy (XPS) was analyzed with an XPS machine (Escalab 250Xi, Thermo Fisher, USA) equipped with an Al Ka excitation source. The thermal stability of the samples was measured with a thermogravimetry-differential scanning calorimetry analyzer (TG-DSC, TG209F1, NETZSCH, Germany) at a heating rate of $5^{\circ} \mathrm{C} \cdot \mathrm{min}^{-1}$ under Ar atmosphere from 25 to $1400{ }^{\circ} \mathrm{C}$. The viscosity and electrical conductivity of the solutions were measured by a viscometer (VM-10A, Sekonic, Japan) and conductivity meter (DDS-307, INESA Scientific Instrument Co., $\mathrm{Ltd}$, China) at a constant temperature of $25^{\circ} \mathrm{C}$, respectively.

Nitrogen $\left(\mathrm{N}_{2}\right)$ adsorption-desorption isotherms were tested by a specific surface \& pore size analysis instrument (BeiShiDe 3H-2000PS1). The Brunauer-Emmett-Teller (BET) and BarretJoyner-Halenda $(\mathrm{BJH})$ methods were used to calculate the specific surface area and pore size 
distribution, respectively. The volume density $\left(\rho_{v}\right)$ of the samples was calculated with the mass divided by volume. The true density $\left(\rho_{t}\right)$ of the samples was tested by a liquid densimeter (XPE205, Mettler Toledo). Then the porosity of the samples was calculated by formula 1:

$$
\text { Porosity }=\left(1-\frac{\rho_{v}}{\rho_{t}}\right) \times 100 \%
$$

\subsection{Mechanical properties measurements}

Mechanical tensile tests were conducted using a materials testing machines (Testometric Micro 350, Testometric, England) with a loading rate of $1 \mathrm{~mm} \cdot \mathrm{min}^{-1}$. The test samples were prepared in size of $20 \mathrm{~mm} \times 3 \mathrm{~mm}$. The flexibility test of the samples was measured on a flexibility tester (FlexTest, Hunan Nanoup Printed Electronics Technology Co., Ltd, Hunan, China).

\subsection{Thermal conductivity measurements}

The thermal conductivity of the samples was measured by a thermal conductivity tester (Hot Disk TPS 2500S, Sweden) according to the testing standard of ISO 22007-2:2015. The samples were cut with a length and width of $30 \mathrm{~mm} \times 30 \mathrm{~mm}$ and thickness of 10 12 $\mathrm{mm}$ for thermal conductivity determination.

The IR transmissivity $(T)$ of the fiber membranes was tested on a Fourier transform infrared spectrometry measurement (FT-IR, Avatar 360, Nicolet). Then the effective IR extinction coefficient $\left(e^{*}\right)$ of the membranes was calculated by the formula 2 [17]:

$$
e^{*}=-\frac{1}{\rho_{v} l} \ln T
$$

where $l$ was the thickness of sample, respectively.

\section{Results and discussion}




\subsection{Morphology and microstructures}

The preparation process and formation mechanism of the MSUFs were illustrated in Fig. 1a. The preparation process of the MSUFs mainly included four procedures: preparation of ES, electrospinning of the ES, thermal curing of the as-spun PFs and pyrolysis of the thermal cured PFs (Fig. S1). Due to the simplicity of electrospinning technique, scaling up the fabrication of MSUF membranes was feasible. As shown in Fig. S1, a large piece of flexible MSUF membrane with size of $29 \times 29 \mathrm{~cm}^{2}$ was prepared. In order to investigate the transformation mechanism of the multichannel structure, the TG analysis of the PS and cured PF-10 fibers was carried. As shown in Fig. S2, the TG curve of PS delivers a significant mass loss of about $100 \%$ between $30^{\circ} \mathrm{C}$ and $430{ }^{\circ} \mathrm{C}$, indicating that the PS decomposed completely during the pyrolysis process. Noticeably, there was a two-stage thermal degradation $\left(300 \sim 430{ }^{\circ} \mathrm{C}\right.$ and $\left.430 \sim 600{ }^{\circ} \mathrm{C}\right)$ in the TG curve of cured PF-10, which should be ascribed to the decomposition of PS and ceramic transformation of the PR and $\mathrm{Zr}(\mathrm{acac})_{4}$. Therefore, the formation mechanism of the MSUFs could be concluded as follows: the PS was firstly stretched into nanowires within the PFs during the electrospinning process, and then decomposed to generate multichannel pores during the pyrolysis process (Fig. 1a).

As shown in Fig. 1b-e, the prepared MSUFs showed a long continuous fiber morphology and relatively uniform diameter. It could be found that the diameter of MSUFs increased from $0.57 \pm 0.07 \mu \mathrm{m}$ to $2.54 \pm 0.28 \mu \mathrm{m}$ with the PS content increased from $2 \mathrm{wt} \%$ to $18 \mathrm{wt} \%$, as demonstrated in Fig. S3. This phenomenon could be contribute to the increasing viscosity and decreasing electrical conductivity of the corresponding ES (Fig. S4), which resulted in the stretching and whipping of the jet by the electrical field force decreased [23].

The cross-section SEM images of a single fiber confirmed the successful introduction of abundant channel pores into the fibers (Fig. 1f-i). It could be found that the pore structure of the 
MSUFs was easily controlled by changing the content of PS from $2 \mathrm{wt} \%$ to $18 \mathrm{wt} \%$. With the PS content increasing, both channel size and channel numbers inside each MSUF increased accordingly (Fig. 1f-i). Of note, when the PS content increased up to $18 \mathrm{wt} \%$, there were some incomplete pores appeared on the cross section of fiber, and some grooves could be observed on the surface of fibers (Fig. 1i). This might be resulted from the high PS content, which could not be completely converted to nanowires within the PFs but agglomerated on the surface of the PFs or directly formed PS fibers. As a result, some grooves formed on the surface of the MSUFs after high temperature pyrolysis. Therefore, proper PS content $(<18 \mathrm{wt} \%)$ might contributed to form multichannel pores within the MSUFs.

(a)
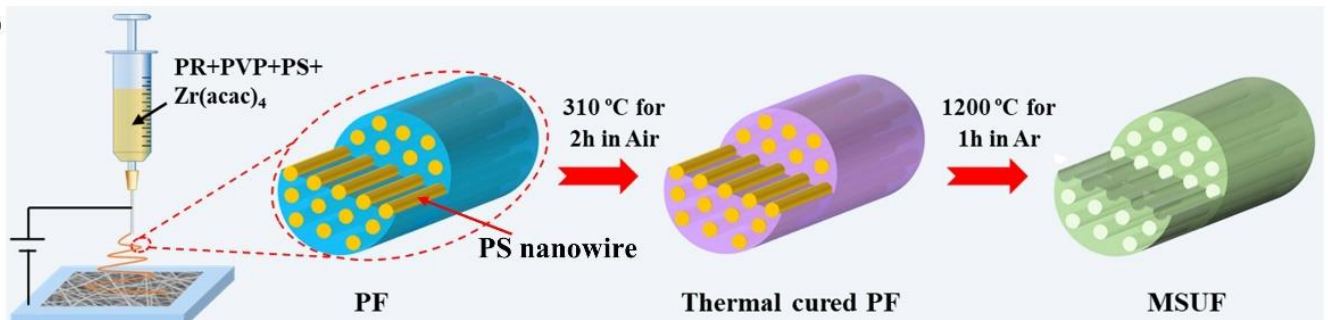

(b)

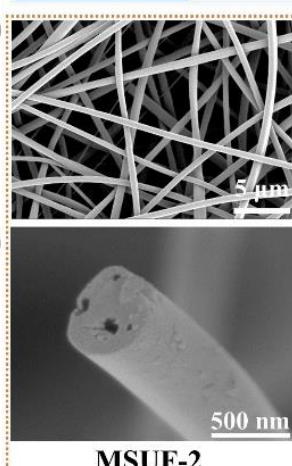

(c)
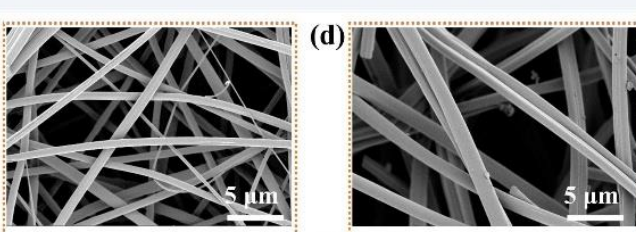

(g)
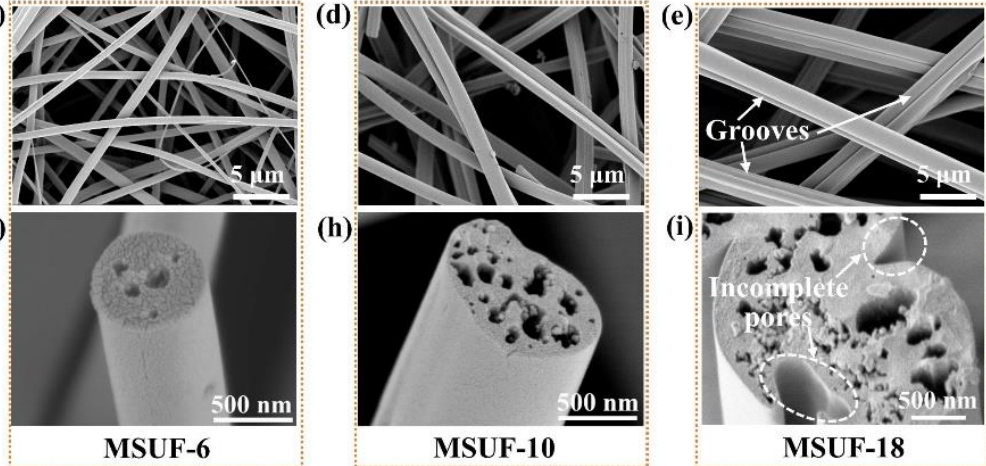

Fig. 1 (a) Schematic illustration of the fabrication process of MSUFs; SEM images of MSUFs based on various PS content: (b,f) 2 wt\%; (c,g) 6 wt\%; (d,h) 10 wt\%; (e,i) 18 wt\%.

The TEM image of MSUF further demonstrated that the channel-like pore structures were well generated throughout the single fiber (Fig. 2a). Moreover, the corresponding HRTEM image (Fig. 
b) revealed that the amorphous phase and $\mathrm{t}-\mathrm{ZrO}_{2}$ crystalline structure of the fiber, with a characteristic lattice fringe distance of $\sim 0.297 \mathrm{~nm}$, corresponding to the (101) plane of $\mathrm{t}-\mathrm{ZrO}_{2}$ phase [24]. The XRD pattern showed that a broad peak located at about $2 \theta=22.5^{\circ}$, corresponding to the amorphous $\mathrm{SiO}_{\mathrm{x}} \mathrm{C}_{\mathrm{y}}$ phase (Fig. 2d) [25]. However, the $\mathrm{ZrO}_{2}$ peaks could not be identified from the XRD pattern, which could be due to the inability of the XRD to detect the component with low contents. The EDS element mapping images showed that the $\mathrm{Si}, \mathrm{Zr}, \mathrm{O}$ and $\mathrm{C}$ elements were homogeneously distributed throughout the fibers, confirming fibers were mainly composed of these elements (Fig. 2c). The results were also verified by the XPS analysis. As shown in Fig. 2e, the characteristic peaks corresponding to $\mathrm{Si} 2 \mathrm{p}, \mathrm{Zr} 3 \mathrm{~d}, \mathrm{O} 1 \mathrm{~s}$ and $\mathrm{C} 1 \mathrm{~s}$ were clearly observed in the XPS survey. Further, the microstructure of the fibers was characterized by the Raman analysis. As shown in Fig. 2f, two main strong peaks were detected at $1350 \mathrm{~cm}^{-1}$ and $1580 \mathrm{~cm}^{-1}$, which correspond to the D and G bands of free carbon, respectively. Moreover, there were two small peaks located at $464 \mathrm{~cm}^{-1}$ and $840 \mathrm{~cm}^{-1}$, which belonged to the $\mathrm{Si}-\mathrm{O}-\mathrm{Si}$ and $\mathrm{Si}-\mathrm{C}$ mode of the $\mathrm{SiO}_{\mathrm{x}} \mathrm{C}_{\mathrm{y}}$ phase, respectively [26]. The results indicated that the MSUFs mainly composed of $\mathrm{SiO}_{\mathrm{x}} \mathrm{C}_{\mathrm{y}}, \mathrm{ZrO}_{2}$ and free carbon phases. 
(a)

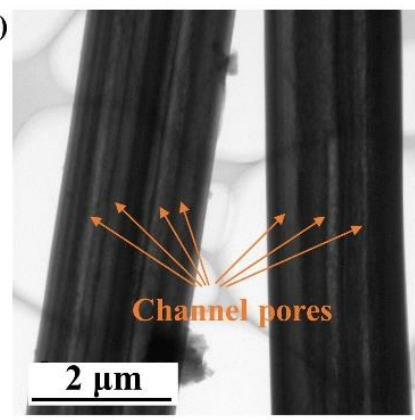

(d)

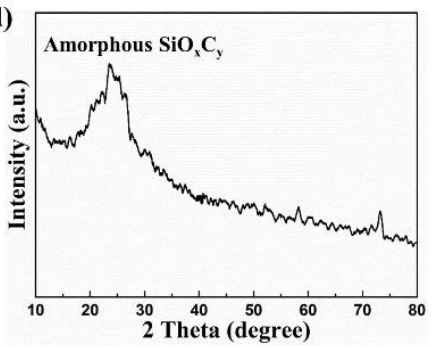

(b)

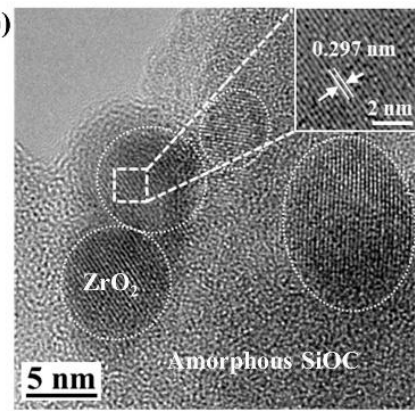

(e)

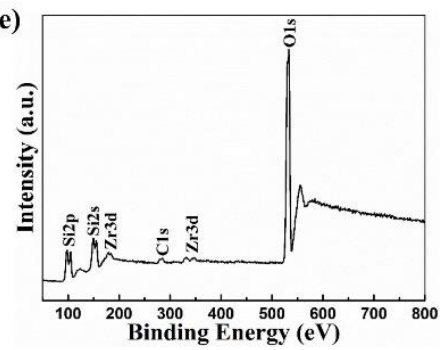

(c)
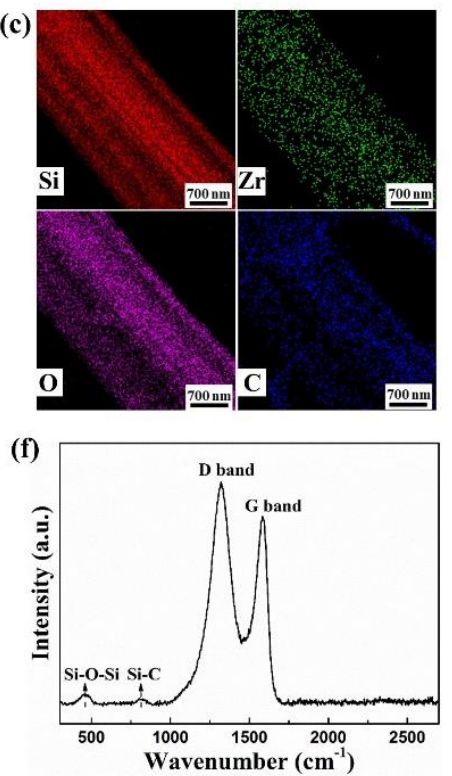

Fig. 2 (a) TEM image of MSUF-10; (b) HRTEM images of MSUF-10; (c) TEM-EDS mapping of MSUF-10 and corresponding elemental mapping images of $\mathrm{Si}, \mathrm{Zr}, \mathrm{O}$ and $\mathrm{C}$; (d) XRD pattern, (e) XPS survey and (f) Raman spectra of MSUF-10.

In order to characterize the porous structure of the MSUFs, the $\mathrm{N}_{2}$ adsorption-desorption measurements were revealed according to the BET method. The adsorption-desorption isotherms and the pore size distribution were shown in Fig. 3a and b. As shown in Fig. 3a, all the MSUFs presented a typical type IV adsorption-desorption isotherms with a H3-type hysteresis loop, indicating the main existence of abundant mesopores in the fibers [27]. The specific surface area of MSUF-2, MSUF-6, MSUF-10, and MSUF-18 calculated by multipoint BET method were $10.85,13.34,24.72$, and $19.8 \mathrm{~m}^{2} \cdot \mathrm{g}^{-1}$, respectively, revealing that the PS content play a significant role in regulating the pore structure of the fibers. It was worth noting that the MSUF-10 possessed the largest surface area compared with other MSUF membranes. In addition, the BJH plot of pore size distribution of MSUF-10 showed a typical broad range of pores (1.89-70 nm) with an average pore size of $16.3 \mathrm{~nm}$ (Fig. 3b). As these results indicated, the proper PS content $(\sim 10 \mathrm{wt} \%)$ in the 
ES would endow the resultant MSUF membranes with enhanced pore structure and large specific surface area, which were beneficial to decreasing density and thermal conductivity of fibers. Furthermore, the volume density and porosity of the resultant MSUF membranes were also tested to further investigate the pore structure, as shown in Fig. 3c. Notably, the MSUF-10 membranes showed lower density $\left(0.044 \mathrm{~g} \cdot \mathrm{cm}^{-3}\right)$ and higher porosity $(97.7 \%)$ than other membranes. The results also evidenced that the MSUF-10 with higher pore structure and porosity than other fibers, which corresponded to the BET analysis. The detailed specific surface area, volume density and porosity parameters of the MSUF membranes were shown in Table S2.
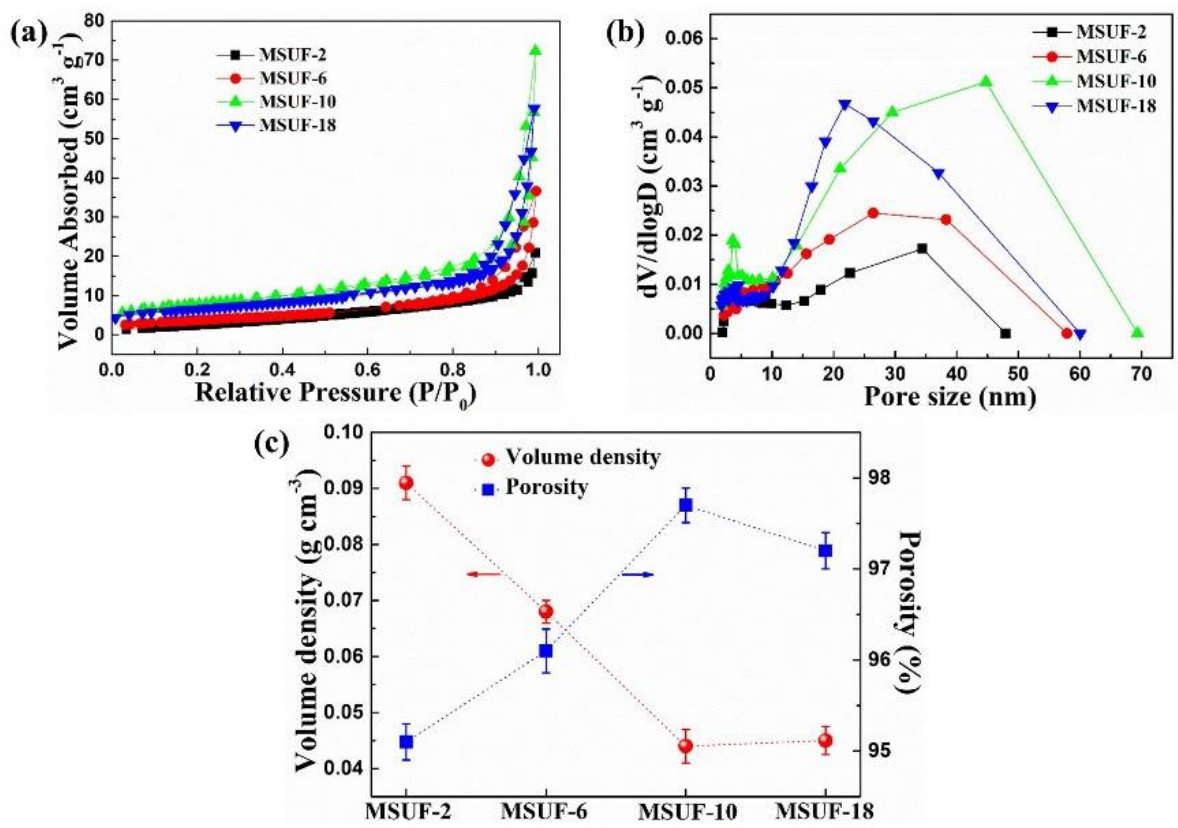

Fig. 3 (a) $\mathrm{N}_{2}$ adsorption-desorption isotherms, (b) BJH pore size distribution curves and (c)

Volume density and porosity of various MSUF membranes.

\subsection{Mechanical properties}

The mechanical properties of the ceramic fiber membranes were closely related to the strength and morphology of single fiber and bonding structure among fibers [23,28]. Thus, the 
transformation of fibers morphology and microstructure could significantly influence the mechanical properties of the prepared MSUF membranes. The mechanical properties of the prepared MSUF membranes were investigated by uniaxial tensile test. The typical tensile stressstrain curves of the membranes were shown in Fig. S5a. The membranes exhibited typically elastic-perfect plastic like response, which attributed to the obviously slipping among fibers during the tensile process. As shown in Fig. S5b, the tensile strength and elastic modulus gradually decreased from 2.36 $\mathrm{MPa}$ to $0.81 \mathrm{MPa}$ and 205.33 $\mathrm{MPa}$ to $40.45 \mathrm{MPa}$ with the PS contents increasing from $2 \mathrm{wt} \%$ to $18 \mathrm{wt} \%$, respectively. The mechanical properties degradation could be ascribed to the decreased strength of single fiber and reduced pack density of the membranes (Fig. 3c), which resulted from the multichannel pores within the fiber increased. In the practical application, thermal insulation materials must be mechanically robust to bear external mechanical forces suffered in the course of mounting, transportation and applications. As can be seen from the Fig. S6, a piece of MSUF-10 membrane (with a size of $10 \times 20 \times 0.8 \mathrm{~mm}$ ) could hang a $20 \mathrm{~g}$ weight without any fracture, demonstrating that the membrane had sufficient strength for practical application. Therefore, the MSUF-10 membranes with low density, high porosity and relatively high tensile strength was chose for further sturdy.

In stark contrast to the brittle nature of conventional ceramic fibers and porous ceramic fibers, the MSUF membranes exhibited super flexibility. They could be easily bended, twisted, knotted and rolled without any cracks (Fig. 4a). The excellent flexibility of the membranes could be further demonstrated by their fast elastic resilience. A movie taken by a high-speed camera showed that a piece of bent MSUF membrane could rebound with a fast recovery speed (Fig. S7), revealing excellent flexibility and elastic performance of the membrane. 
In order to further investigate the super flexibility, robust mechanical properties and durability of the membranes, we bended, twisted and rolled the MSUF membranes at various cycles (10 100). Then the tensile strength was measured and the tensile strength retention was calculated. The schematic of side view of bending, twisting and rolling test was shown in Fig. S8a. Remarkably, the membranes could endure 100 cycles bending, twisting and rolling, no cracks were observed on them (Fig. S8b-d), except for a slight tensile strength retention decrease (Fig. 4b). The tensile strength retention was up to $87.1 \%, 79.2 \%$, and $62.1 \%$ after 100 cycles twisting, bending and rolling tested (Fig. 4b), respectively. The results highlighted the membranes with high flexibility, strength and durability. The bending deformation of a piece of MSUF membrane and a single fiber was further analyzed by the SEM. As shown in Fig. 4c, the membrane could tolerate extreme deformation without generating fractures. Moreover, a single fiber was able to bear large bending deformation with a bending angle up to $145^{\circ}$ without any cracks (Fig. 4d), revealing excellent bending properties of the fiber.

Flexibility was a long-standing challenge in ceramic materials, especially in porous ceramic materials because the cracks were easily formed from the pores and propagate rapidly [23,29]. Benefiting from the unique composition and microstructure, the prepared MSUF membranes exhibited outstanding flexibility. Based on the systematical analysis of the fiber's composition and microstructure, the plausible flexibility mechanism of the MSUF membranes could be understood in multiscale (Fig. 4e). At macroscopic level, the membranes composed of entangled and random fibers, which could freely move and bear large deformation when the external force loaded on them. Therefore, the bending stress would be easily released by the slipping and bending of fibers during the bending process of the membranes [24,30]. At microscale level, there were numerous $\mathrm{t}-\mathrm{ZrO}_{2}$ nanograins wrapped in the amorphous $\mathrm{SiO}_{\mathrm{x}} \mathrm{C}_{\mathrm{y}}$ phase. Theses nanograins could inhibit the 
initiation and propagation of cracks or lead to crack redirection [29]. Moreover, the stress could induce the transfer of $\mathrm{t}-\mathrm{ZrO}_{2}$ to $\mathrm{m}-\mathrm{ZrO}_{2}$ accompanied with volume expansion, which could also heal some cracks [31]. At nanoscale level, the amorphous $\mathrm{SiO}_{\mathrm{x}} \mathrm{C}_{\mathrm{y}}$ phase play a major factor to the flexible MSUFs, which lack microstructural defects and can dispersed stress and bear enormous deformation [24]. It had been found that the network structure composed of $\mathrm{SiO}_{4}$ tetrahedron were relatively flexible. The bond angle and bond length of the $\mathrm{Si}-\mathrm{O}-\mathrm{Si}$ and O-Si-O bonds within $\mathrm{SiO}_{4}$ tetrahedron could vibrate at a wide distribution range to release some external stress [24]. Correspondingly, the $\mathrm{SiO}_{\mathrm{x}} \mathrm{C}_{\mathrm{y}}$ was formed when some carbon atoms replaced the oxygen atom in the $\mathrm{SiO}_{4}$ tetrahedron. Therefore, the amorphous $\mathrm{SiO}_{\mathrm{x}} \mathrm{C}_{\mathrm{y}}$ phase inherited the excellent flexibility of the $\mathrm{SiO}_{4}$ tetrahedron. Owing to the above mechanisms, the MSUFs could avoid stress concentration and yield large deformation.

(a)

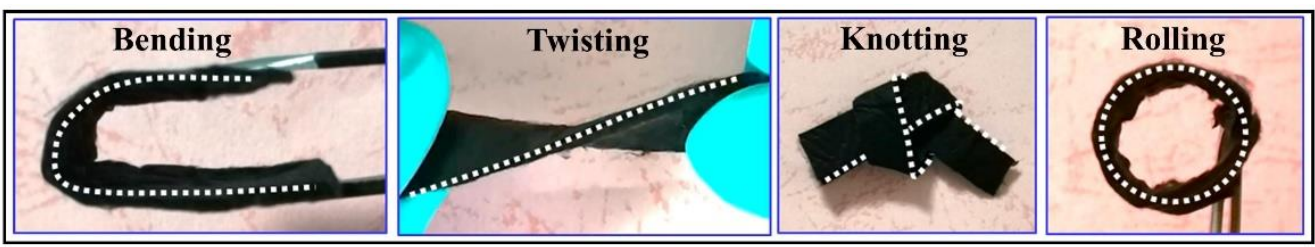

(b)

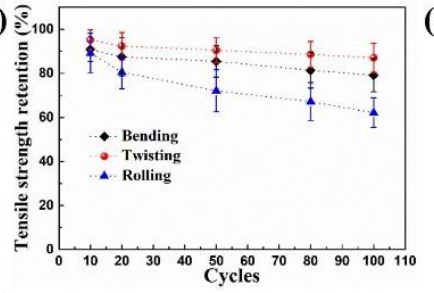

(c)

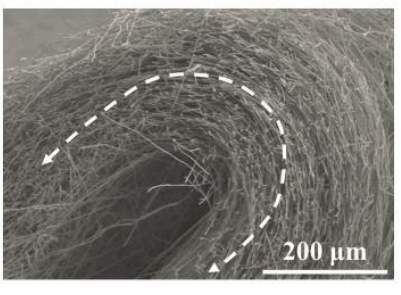

(d)

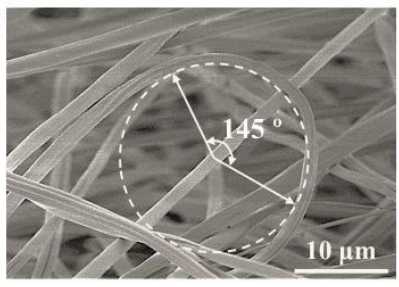

(e)

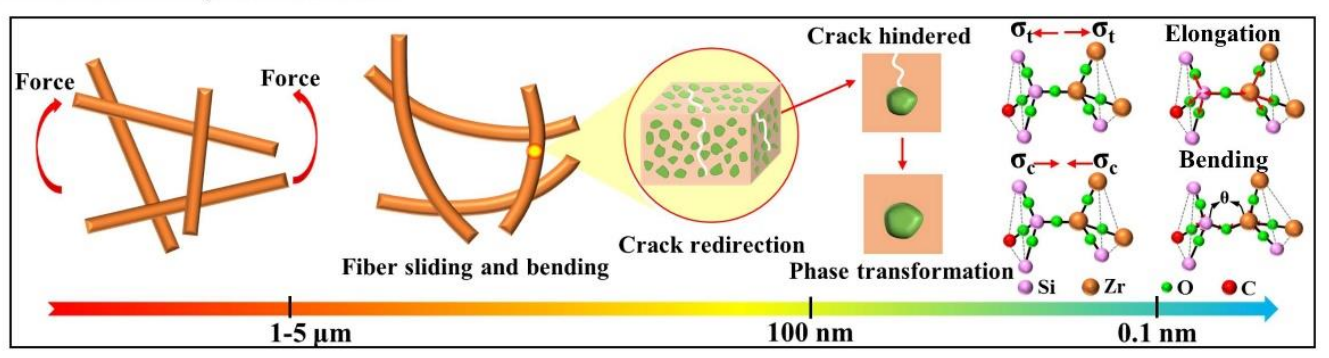

Fig. 4 (a) High flexibility demonstrated by bending, twisting, knotting and rolling test of a piece of MSUFs membrane; (b) Tensile strength retention versus 100 cycles bending, twisting and 
rolling tests; (c) SEM image of the bent MSUF membrane; (d) SEM image showing the bending angle of a single MSUF; (e) Schematic of the flexibility mechanism of the MSUF membranes.

\subsection{Thermal stability and thermal shock resistance}

Thermal stability and thermal shock resistance were also critical criterion to evaluate application safety of thermal insulators. The thermal stability of the MSUF membranes was illustrated by TG analysis from $25^{\circ} \mathrm{C}$ to $1400{ }^{\circ} \mathrm{C}$ in $\mathrm{Ar}$ atmosphere. As shown in Fig. 5a, the mass was stable up to $1400{ }^{\circ} \mathrm{C}$ without obvious change, indicating excellent thermal stability of the MSUF membranes. Furthermore, the MSUF membranes treated at $1400{ }^{\circ} \mathrm{C}$ for $2 \mathrm{~h}$ in $\mathrm{Ar}$ could folded and then recovered their original shape without any cracks (inset in Fig. 5a). Besides, the surface of the heat-treated MSUFs were still smooth without obvious defects, similar to the as-prepared MSUFs (Fig. 5b). The results also evidenced that the MSUF membranes could withstand high temperature and maintain their high flexibility for long periods. Except for, the MSUF membranes exhibited excellent fire resistance and high flexibility at high temperatures, which was demonstrated by in situ bending tests while heated with a butane blowlamp to $\sim 1000{ }^{\circ} \mathrm{C}$ (Fig. S9a). No obvious structural changes or cracks were observed when the MSUF membranes were exposed to high temperatures (Fig. S9a), illustrating their high thermal stability and flexibility at high temperatures.

Apart from the high temperature flexibility, the MSUF membranes also exhibited high flexibility at low temperature. As shown in Fig. S9b, the MSUF membranes remained flexibility and could be bended in liquid $\mathrm{N}_{2}\left(-196^{\circ} \mathrm{C}\right)$. When the load was released, the MSUF membranes returned to their original shape without obvious cracks (Fig. S9b), demonstrating their high flexibility at low temperatures. 
High thermal shock resistance was a vitally important feature for materials in many application areas, especially for aerospace applications $[2,4]$. The thermal shock tests were carried by heating the MSUF membranes via butane blowlamp for $30 \mathrm{~s}$, and then immersed into liquid nitrogen (-196 $\left.{ }^{\circ} \mathrm{C}\right)$ for $30 \mathrm{~s}$. We endured the thermal shock tests of the MSUF membranes at various (10 100) cycles, and their flexibility and tensile strength retention were investigated. Unexpectedly, after enduring rapid thermal shock for 100 cycles, the MSUF membranes still maintain their original morphology and high flexibility, and no cracks appeared (Fig. 5c and inset in Fig. 5d). Moreover, the tensile strength retention of the membranes does not change obviously (Fig. 5d). The results indicated that the MSUF membranes with high structural stability and thermal shock resistance at rapid temperature changes, which were vitally critical for practical application in extreme environments.

(a)

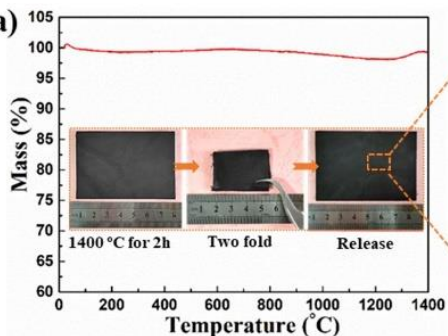

(c)

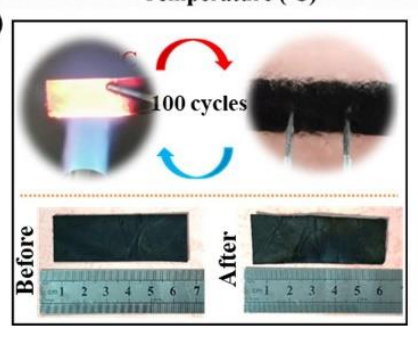

(b)

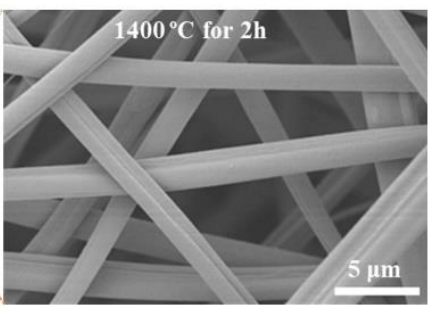

(d)

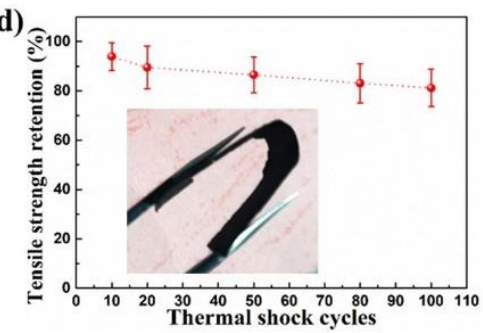

Fig. 5 (a) TG curve of the MSUFs in Ar atmosphere from 25 to $1400^{\circ} \mathrm{C}$ and macroscopic images of MSUF membranes after heat treated at $1400^{\circ} \mathrm{C}$ for $2 \mathrm{~h}$ (Inset); (b) SEM image of the MSUF membranes after heat treated at $1400{ }^{\circ} \mathrm{C}$ for $2 \mathrm{~h}$; (c) Schematic of rapid thermal shock test for 100 cycles and optical photographs of MSUF membranes before and after 100 cycles thermal shock 
tested; (d) Tensile strength retention of MSUF membranes versus thermal shock cycles and optical photographs show high flexibility of the MSUF membranes after tested (Inset).

\subsection{Thermal insulation performance}

Generally, the total thermal conductivity $(\lambda)$ of ceramic fiber membranes is mainly composed of three components: solid thermal conductivity $\left(\lambda_{s}\right)$, gaseous thermal conductivity $\left(\lambda_{g}\right)$ and radiation thermal conductivity $\left(\lambda_{r}\right)[18,20]$. At ambient temperature, the contribution of $\lambda_{r}$ to $\lambda$ is small and can be neglected. Therefore, the $\lambda$ can be approximately equal to the sum of $\lambda_{s}$ and $\lambda_{g}$ at ambient temperature. However, on the basis of Stefan-Boltzmann law, the $\lambda_{r}$ is proportional to the third power of the temperature, which indicates that the $\lambda_{r}$ plays an important role in heat transfer at high temperatures [32]. The $\lambda_{r}$ can be calculated by the formula 3 [32]:

$$
\lambda=\frac{16 n^{2} \sigma}{3 e^{*} \rho} T^{3}
$$

where $n, \sigma, \rho$ and $T$ are the effective refractive index, Stefan-Boltzmann constant, sample density, and temperature. In general, $\lambda_{s}$ can be reduced by decreasing the bulk density, $\lambda_{g}$ can be decreased by narrowing the pore size of the material and $\lambda_{r}$ can be reduced by enhancing the $e^{*}[18]$. Owing to the unique multichannel structure and components, the as-prepared MSUF membranes exhibited excellent thermal insulation performance, which makes it a promising thermal insulating material for application in the field of aerospace and aircrafts.

As shown in Fig. S10, we put a fresh flower on a piece of MSUF membrane with $8 \mathrm{~mm}$ thickness and heated it using an alcohol lamp. After 3 minutes of heating, the flower remained fresh, revealing high thermal insulation performance of the membrane (Fig. S10). The corresponding IR images also illustrate the excellent thermal insulation performance of the membrane (Fig. S10). 
Benefiting from the high strength and flexibility of the MSUF membranes, our MSUF membranes have remarkable advantage in practical applications, especially in the field of protecting complex curved surface. As shown in Fig. 6a, a piece of MSUF membrane with a thickness of 5 mm could be wrapped around the nozzle of a butane torch. The IR images showed that the temperature of the exposed nozzle increases rapidly up to $\sim 700^{\circ} \mathrm{C}$ after $1 \mathrm{~min}$, while the temperature of the membrane increased slowly to $\sim 43.7^{\circ} \mathrm{C}$. The results also indicated that MSUF membranes possessed superior thermal insulation performance.

Fig. $6 \mathrm{~b}$ showed the $\lambda$ at ambient temperature of the prepared various MSUF membranes. Obviously, the MSUF-10 membranes presented a lower $\lambda\left(0.041 \mathrm{~W} \mathrm{~m}^{-1} \cdot \mathrm{K}^{-1}\right)$ than other membranes. The low $\lambda$ of the membranes could be ascribed to their low density and high porosity structure (Fig. 3c), which decreased $\lambda_{s}$ and $\lambda_{g}$. At high-temperatures, the $\lambda_{r}$ plays a major role in heat transfer. The $e^{*}$ could be used to evaluate the $\lambda_{r}$ at high-temperatures. Higher $e^{*}$ means lower $\lambda_{r}$ at high-temperatures according to the formula 3. Therefore, the $e^{*}$ versus IR wavelength from 2.5 7 $\mu \mathrm{m}$ of various MSUF membranes were tested, as shown in Fig. 6c. Of note, the MSUF-10 membranes presented higher $e^{*}$ over wide IR wavelength range than the other membranes, revealing low $\lambda_{r}$ at high temperatures. The lower $\lambda_{r}$ could be the numerous channels enhance the reflecting and absorption of IR radiation [21].

Based on the above analysis, the thermal insulation mechanisms of MSUFs could be attributed to three aspects (Fig. 6d). First, the multichannel pores lengthen the path of solid heat transfer and restrict the gaseous heat conduction, which lead to the decline of $\lambda_{s}$ and $\lambda_{g}[18,19]$. Second, the multichannel structure makes the IR radiation multiple reflect and absorb, resulting in the lowering of $\lambda_{r}$ [21]. Third, the phase interfaces among the $\mathrm{SiO}_{\mathrm{x}} \mathrm{C}_{\mathrm{y}}, \mathrm{ZrO}_{2}$ and free carbon phases enhance the 
phonon scattering and the $\mathrm{SiO}_{\mathrm{x}} \mathrm{C}_{\mathrm{y}}$ and free carbon phases have high $e^{*}$, which also contribute to the decrease of $\lambda_{s}$ and $\lambda_{r}$, respectively [32].
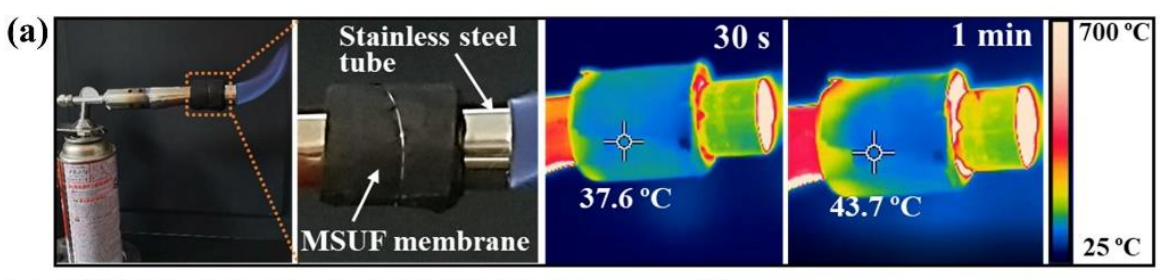

(b)

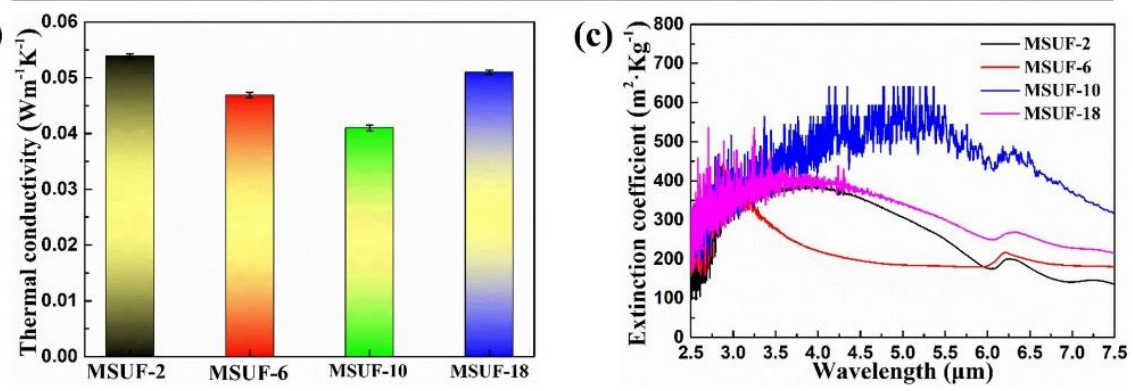

(d)

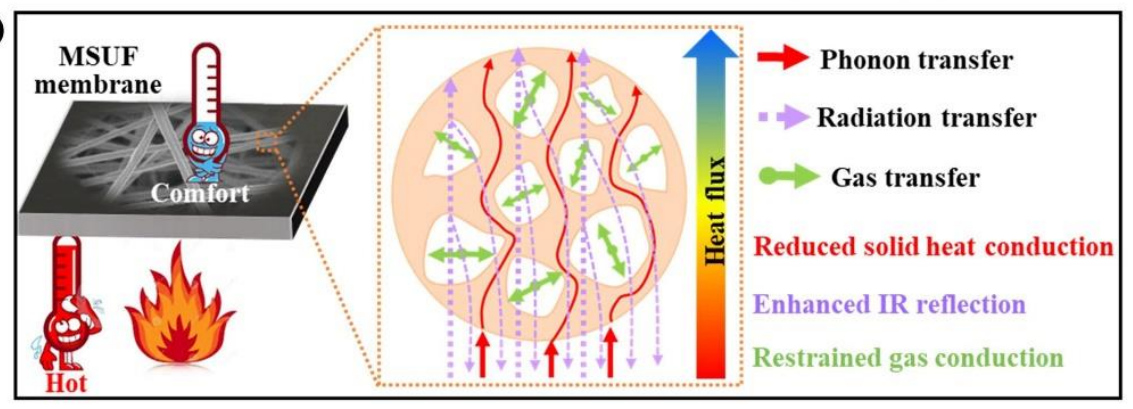

Fig 6 (a) Photo and IR images of MSUF membrane wrap around the nozzle of a butane torch;

(b) Thermal conductivity of various MSUF membranes at ambient temperature; (c) $e^{*}$ versus IR wavelength from 2.5-7 $\mu \mathrm{m}$; (d) Thermal insulation mechanisms of MSUF membranes.

Fig. 7 sums up the extensive thermal insulation performances of the reported ceramic fiber membranes at various temperatures. Notably, the MSUF membranes exhibit superior thermal insulation performance than other reported ceramic fiber membranes [14,16,33-35]. Furthermore, the prepared MSUF membranes possess high temperatures thermal stability up to $1400{ }^{\circ} \mathrm{C}$. Therefore, in addition to the super flexibility, the resulting MSUF membranes present a 
combination of low thermal conductivity and high temperature stability, indicating their promising applications in high temperature thermal insulation.

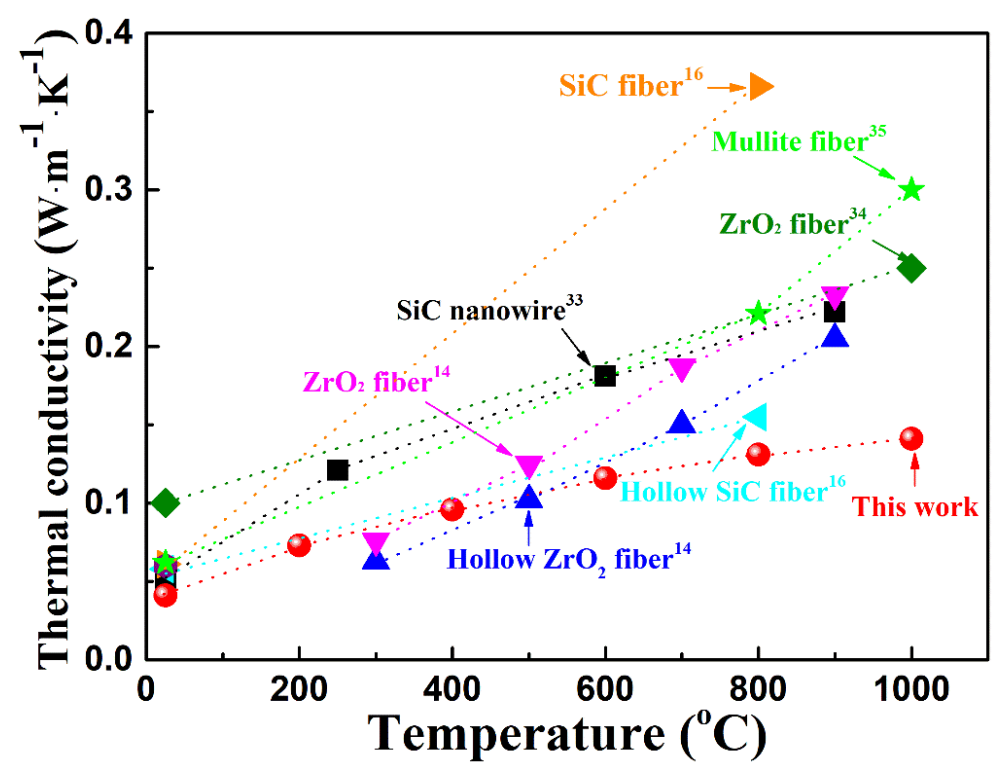

Fig. 7 Thermal conductivity versus temperature of ceramic fiber membranes.

\section{Conclusions}

In summary, we designed multichannel structured MSUF membranes composed of $\mathrm{ZrO}_{2}$, $\mathrm{SiO}_{\mathrm{x}} \mathrm{C}_{\mathrm{y}}$ and free carbon phases through electrospinning technique by selecting polystyrene as the pore-forming template to regulate the pore structure. Owing to the unique components, the asprepared MSUFs exhibits integrated properties of excellent fire resistance, thermal shock resistance, temperature-invariant flexibility over a wide temperature range $\left(-196 \sim 1000{ }^{\circ} \mathrm{C}\right)$ and high temperature stability up to $1400{ }^{\circ} \mathrm{C}$. Remarkably, the fancy multichannel structure and components endow the MSUF membranes with excellent thermal insulation performance with low thermal conductivity $\left(0.041 \mathrm{~W} \mathrm{~m}^{-1} \cdot \mathrm{K}^{-1}\right.$ at ambient and $0.141 \mathrm{~W} \mathrm{~m}^{-1} \cdot \mathrm{K}^{-1}$ at $\left.1000^{\circ} \mathrm{C}\right) . \mathrm{In}$ conclusion, 
the successful fabrication of such flexible porous ceramic fibers with low thermal conductivity holds great promise for high temperature thermal insulation under extreme conditions.

\section{Corresponding Author}

Email for Yingde Wang: wangyingde@ nudt.edu.cn

Email for Bing Wang: bingwang@ nudt.edu.cn

\section{Declaration of Competing Interest}

The authors declare that they have no known competing financial interests or personal relationships that could have appeared to influence the work reported in this paper.

\section{Funding Sources}

This work is supported by the Defense Industrial Technology Development Program (JCKY2017****), National Natural Science Foundation of China (51773226, 52002400, 51872329), Natural Science Foundation of Hunan Province (2018JJ3603) and Research Project of NUDT (ZK20-08).

\section{References}

1. Uyanna O, Najafi H, Thermal protection systems for space vehicles: A review on technology development, current challenges and future prospects. Acta Astronaut 2020, 176: 341-356.

2. Christidis G, Koch U, Poloni E, et al. Broadband, high-temperature stable reflector for aerospace thermal radiation protection. ACS Appl Mater Interfaces 2020, 12: 9925-9934.

3. Sziroczak D, Smith H, A review of design issues specific to hypersonic flight vehicles. Prog Aerosp Sci 2016, 84: 1-28. 
4. Randall P, Meador M, Jana S, Tailoring mechanical properties of aerogels for aerospace applications. ACS Appl Mater Interfaces 2011, 3: 613-626.

5. $\mathrm{Xu} \mathrm{X,} \mathrm{Zhang} \mathrm{QQ,} \mathrm{Hao} \mathrm{ML,} \mathrm{et} \mathrm{al.} \mathrm{Double-negative-index} \mathrm{ceramic} \mathrm{aerogels} \mathrm{for} \mathrm{thermal}$ superinsulation. Science 2019, 363: 723-727.

6. Dou LY, Cheng XT, Zhang XX, et al. Temperature-invariant superelastic, fatigue resistant, and binary-network structured silica nanofibrous aerogels for thermal superinsulation. J Mater Chem A 2020, 8: 7775-7783.

7. Su L, Wang HJ, Niu M, et al. Ultralight, recoverable, and high-temperature-resistant SiC nanowire aerogel. ACS Nano 2018, 12: 3103-3111.

8. Si Y, Wang X, Dou LY, et al. Ultralight and fire-resistant ceramic nanofibrous aerogels with temperature-invariant superelasticity. Adv Sci 2018, 7: eaas8925.

9. Zhang XS, Wang B, Wu N, et al. Multi-phase SiZrOC nanofibers with outstanding flexibility and stability for thermal insulation up to $1400^{\circ} \mathrm{C}$. Chem Eng J 2021, 410: 128304.

10. Jia C, Li L, Liu Y, et al. Highly compressible and anisotropic lamellar ceramic sponges with superior thermal insulation and acoustic absorption performances. Nat Commun 2020, 11: 3732.

11. Tang XB, Sun AH, Chu CY, et al. A novel silica nanowire-silica composite aerogels dried at ambient pressure. Mater Des 2017, 115: 415-421.

12. Si Y, Mao X, Zheng HX, et al. Silica nanofibrous membranes with ultra-softness and enhanced tensile strength for thermal insulation. RSC Advances 2015, 5: 6027-6032. 
13. Dombrovsky LA, Quartz-fiber thermal insulation: infrared radiative properties and calculation of radiative conductive heat transfer. J Heat Transfer 1996, 118: 408-414.

14. Wang TC, Zhang $\mathrm{ZH}$, Dai $\mathrm{CH}$, et al. Amorphous silicon and silicates-stabilized $\mathrm{ZrO}_{2}$ hollow fiber with low thermal conductivity and high phase stability derived from a cogon template. Ceram Int 2019, 45: 7120-7126.

15. Lo YW, Wei CJ, Hsueh $\mathrm{CH}$, Low thermal conductivity of porous $\mathrm{Al}_{2} \mathrm{O}_{3}$ foams for $\mathrm{SOFC}$ insulation. Mater Chem Phys 2011, 129: 326-330.

16. Tian Q, Wu N, Wang B, et al. Fabrication of hollow SiC ultrafine fibers by single-nozzle electrospinning for high-temperature thermal insulation application. Mater Lett 2019, 239: 109-112.

17. Wang B, Wang YD, Effect of fiber diameter on thermal conductivity of the electrospun carbon nanofiber mats. Adv Mater Res 2011, 332: 672-677.

18. Gbewonyo S, Carpenter AW, Gause CB, et al. Low thermal conductivity carbon fibrous composite nanomaterial enabled by multiscale porous structure. Mater Des 2017, 134: 218225.

19. Wang Y, Huang HB, Zhao Y, et al. Self-assembly of ultralight and compressible inorganic sponges with hierarchical porosity by electrospinning. Ceram Int 2020, 46: 768-774.

20. Liang CY, Wang ZF, Wu LN, et al. Light and strong hierarchical porous $\mathrm{SiC}$ foam for efficient electromagnetic interference shielding and thermal insulation at elevated temperatures. ACS Appl Mater Interfaces 2017, 9: 29950-29957. 
21. Zhou J, Hsieh YL, Nanocellulose aerogel-based porous coaxial fibers for thermal insulation. Nano Energy 2019, 68:104305.

22. Yang HE, Wang ZQ, Liu Z, et al. Continuous, strong, porous silk firoin-based aerogel fibers toward textile thermal insulation. Polymers 2019, 11: 1899.

23. Mao X, Bai Y, Yu JY, et al. Flexible and highly temperature resistant polynanocrystalline zirconia nanofibrous membranes designed for air filtration. J Am Ceram Soc 2016, 99: 27602768.

24. Zhang XX, Wang F, Dou LY, et al. Ultrastrong, superelastic, and lamellar multiarch structured $\mathrm{ZrO}_{2}-\mathrm{Al}_{2} \mathrm{O}_{3}$ nanofibrous aerogels with high-temperature resistance over $1300{ }^{\circ} \mathrm{C}$. ACS Nano 2020,14:15616-15625.

25. Liu C, Pan RQ, Hong CQ, et al. Effects of $\mathrm{Zr}$ on the precursor architecture and hightemperature nanostructure evolution of SiOC polymer-derived ceramics. J Eur Ceram Soc. 2016, 36: 395-402.

26. Liu YA, LIU Y, Choi WC, et al. Highly flexible, erosion resistant and nitrogen doped hollow SiC fibrous mats for high temperature thermal insulators. J Mater Chem A 2017, 5: 26642672.

27. Han $\mathrm{C}$, Wang YD, Lei YP, et al. In situ synthesis of graphitic- $\mathrm{C}_{3} \mathrm{~N}_{4}$ nanosheet hybridized Ndoped $\mathrm{TiO}_{2}$ nanofibers for efficient photocatalytic $\mathrm{H}_{2}$ production and degradation. Nano Res 2015, 8: 1199-1209. 
28. Wu H, Pan W, Lin DD, et al. Electrospinning of ceramic nanofibers: Fabrication, assembly and applications. J Adv Ceram 2012, 1: 2-23.

29. Wu N, Wang B, Wang YD, Enhanced mechanical properties of amorphous SiOC nanofibrous membrane through in situ embedding nanoparticles. J Am Ceram Soc 2018, 101: 4763-4772.

30. Shan H R, Si Y, Yu JY, et al. Flexible, mesoporous, and monodispersed metallic cobaltembedded inorganic nanofibrous membranes enable ultra-fast and high-efficiency killing of bacteria. Chem Eng J 2020, 382: 122909.

31. Mamivand M, Zaeem MA, Kadiri HE, Phase field modeling of stress-induced tetragonal-tomonoclinic transformation in zirconia and its effect on transformation toughening. Acta Mater 2014, 64: 208-219.

32. $\mathrm{Xu} \mathrm{L}$, Jiang YG, Feng JZ, et al. Infrared-opacified $\mathrm{Al}_{2} \mathrm{O}_{3}-\mathrm{SiO}_{2}$ aerogel composites reinforced by SiC-coated mullite fibers for thermal insulations. Ceram Int 2015, 41: 437-442.

33. Li BB, Yuan XS, Gao Y, et al. A novel SiC nanowire aerogel consisted of ultralong SiC nanowires. Mater Res Express 2019, 6: 045030.

34. Wang TC, Yu QK, Kong J, et al. Synthesis and heat-insulating properties of yttria-stabilized $\mathrm{ZrO}_{2}$ hollow fibers derived from a ceiba template. Ceram Int 2017, 43: 9296-9302.

35. Zu GQ, Shen J, Wang WQ, et al. Robust, highly thermally stable, core-shell nanostructured metal oxide aerogels as high-temperature thermal superinsulators, adsorbents, and catalysts. Chem Mater 2014, 26: 5761-5772. 


\section{Figures}

(a)
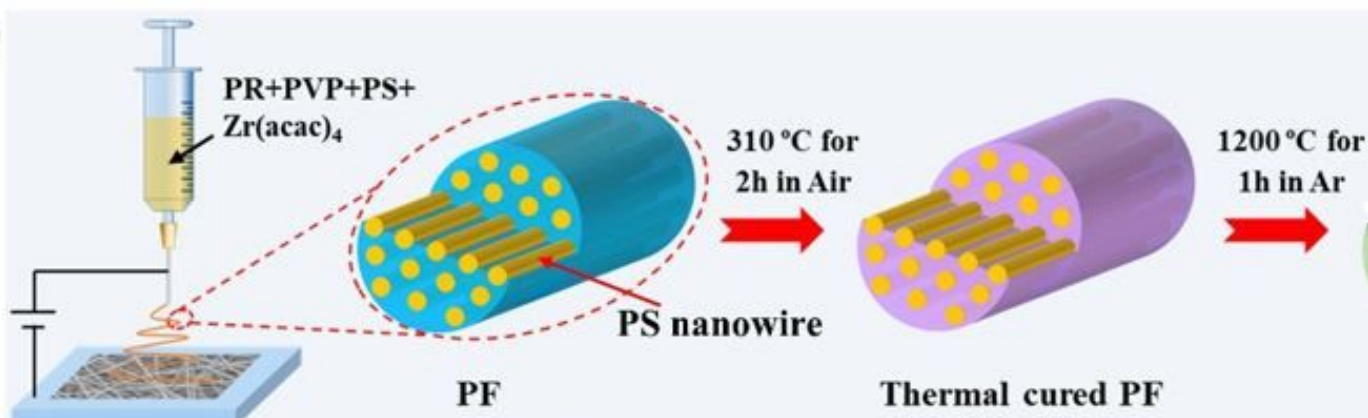

Thermal cured PF

(b)

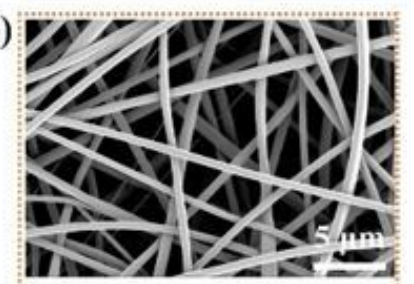

(c)

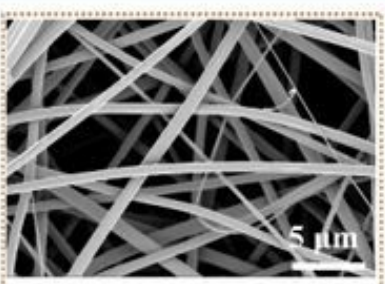

(f)

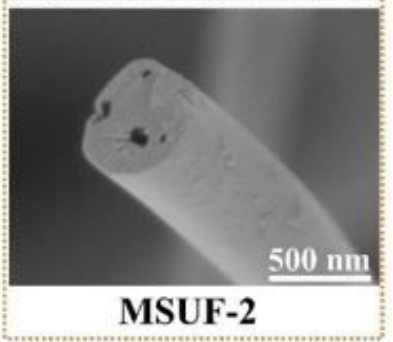

(g)

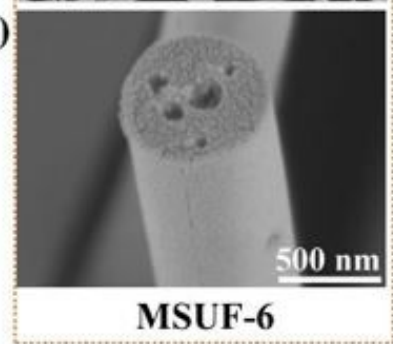

(d)

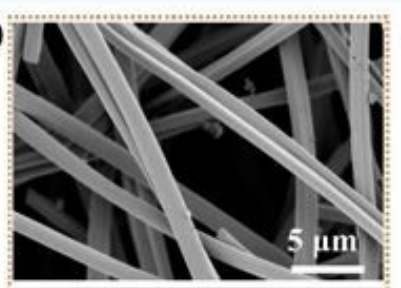

(h)

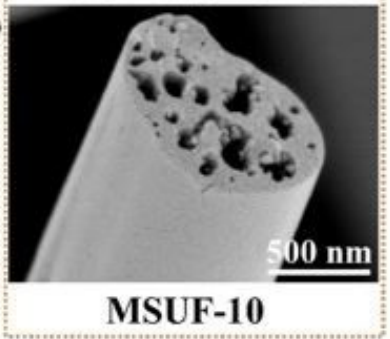

(e)

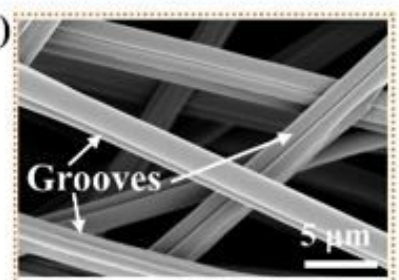

(i)

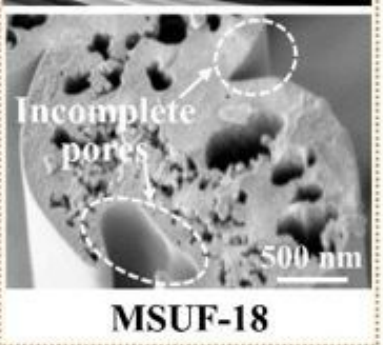

Figure 1

(a) Schematic illustration of the fabrication process of MSUFs; SEM images of MSUFs based on various PS content: (b,f) 2 wt\%; (c,g) 6 wt\%; (d,h) 10 wt\%; (e,i) 18 wt\%. 
(a)

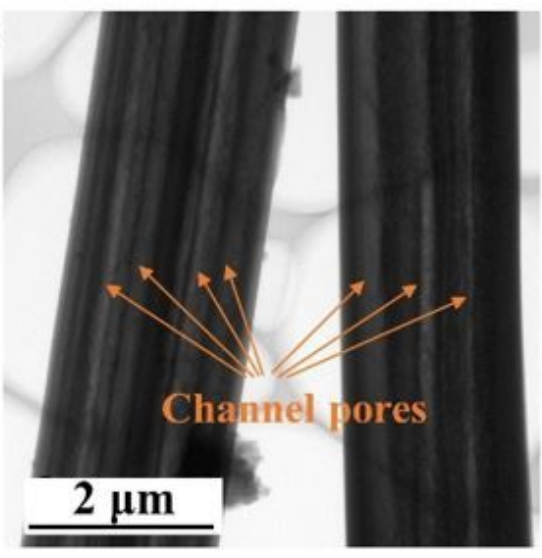

(d)

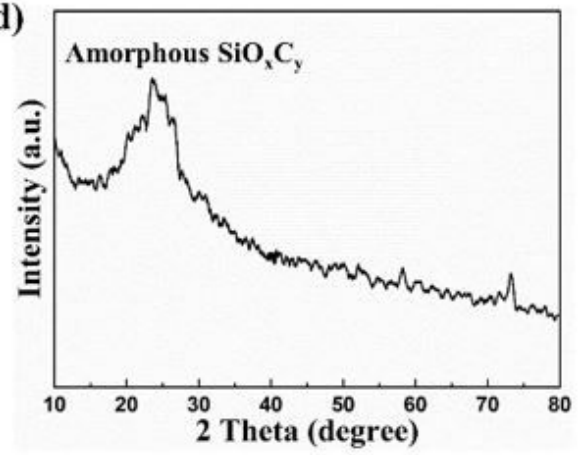

(b)

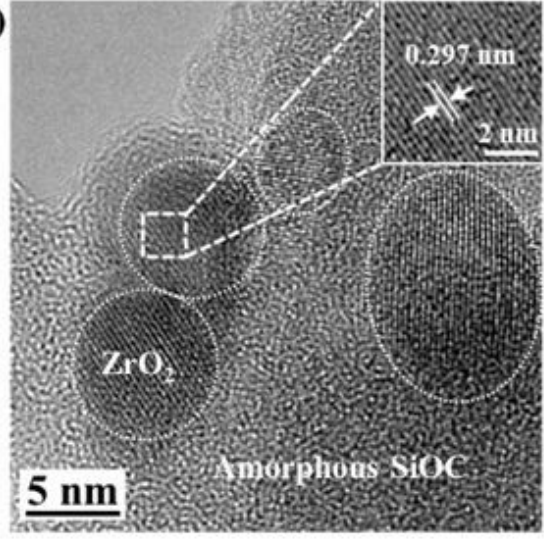

(e)

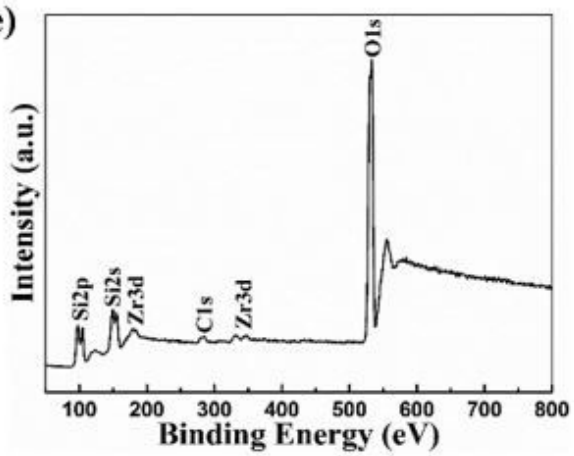

(c)

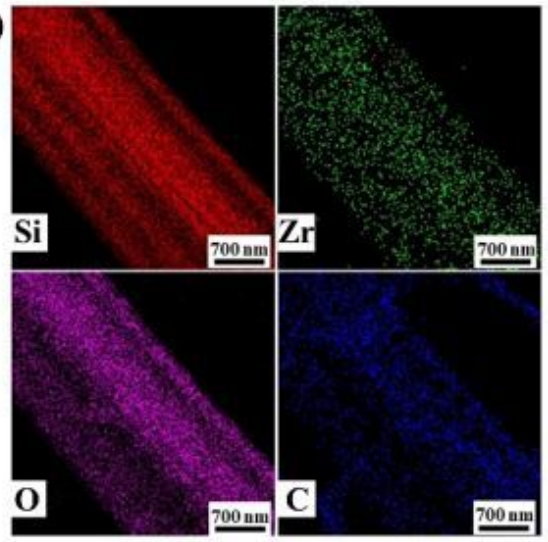

(f)

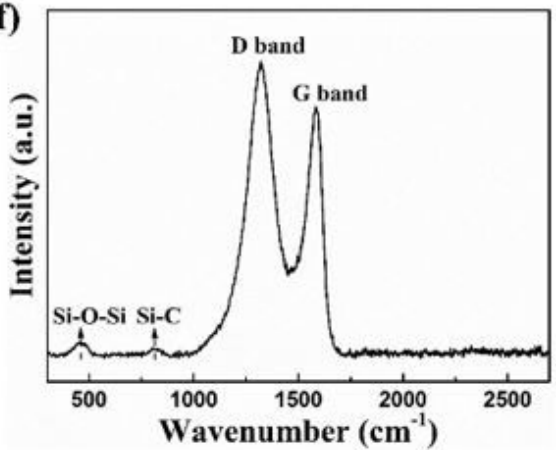

Figure 2

(a) TEM image of MSUF-10; (b) HRTEM images of MSUF-10; (c) TEM-EDS mapping of MSUF-10 and corresponding elemental mapping images of $\mathrm{Si}, \mathrm{Zr}, \mathrm{O}$ and $\mathrm{C}$; (d) XRD pattern, (e) XPS survey and (f) Raman spectra of MSUF-10. 

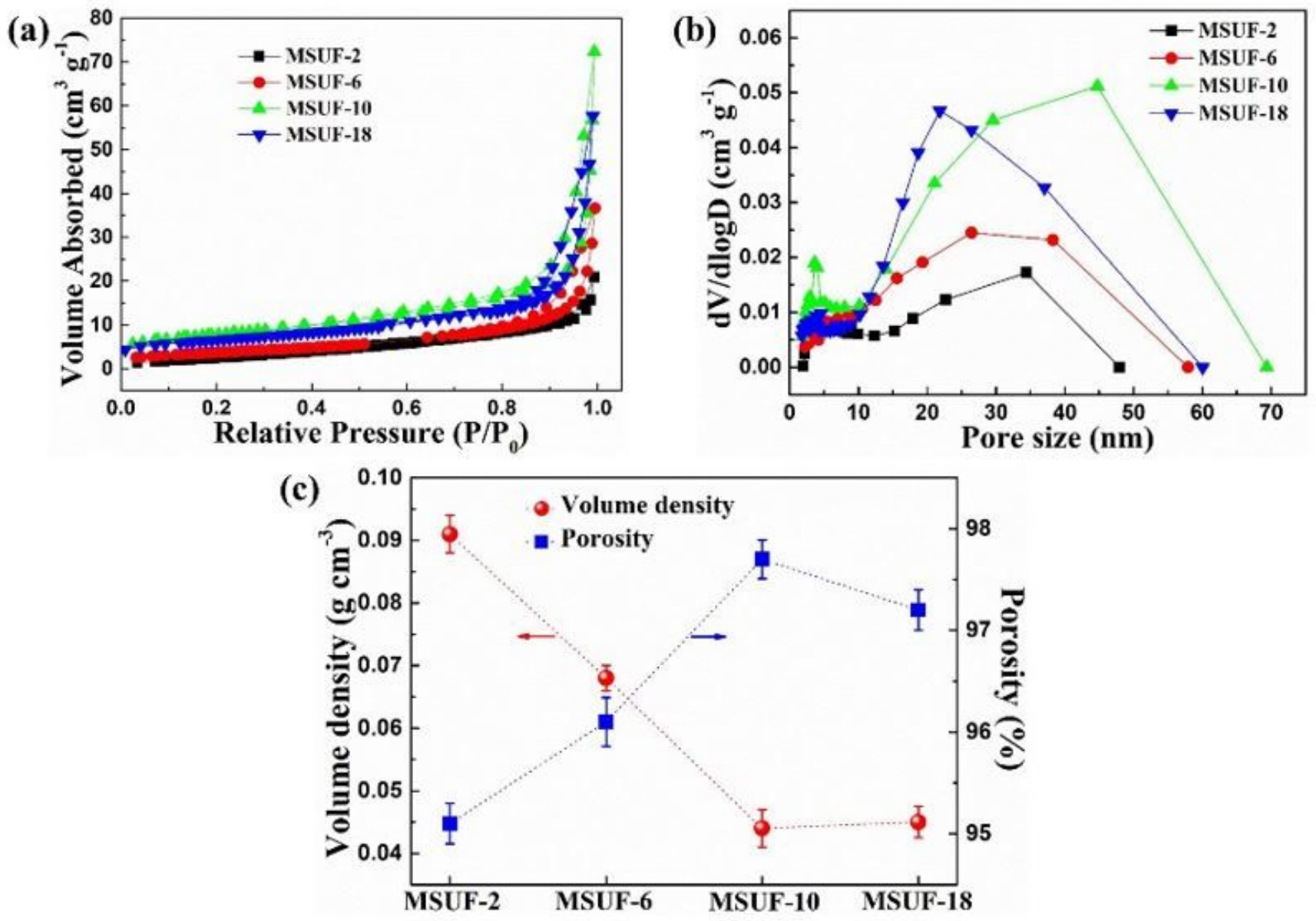

Figure 3

(a) N2 adsorption-desorption isotherms, (b) BJH pore size distribution curves and (c) Volume density and porosity of various MSUF membranes. 
(a)

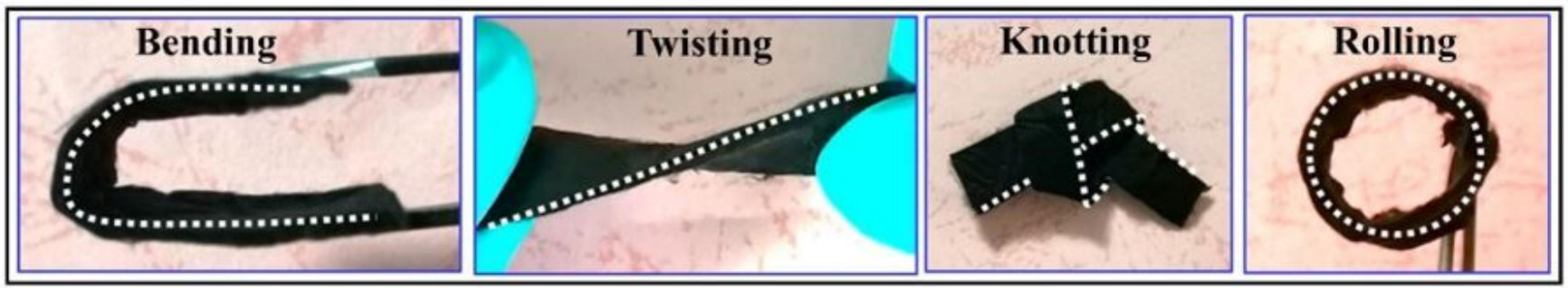

(b)

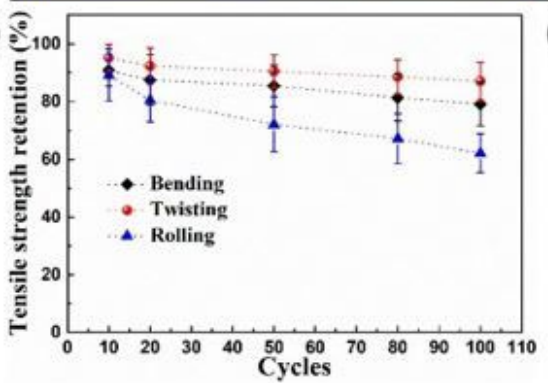

(c)

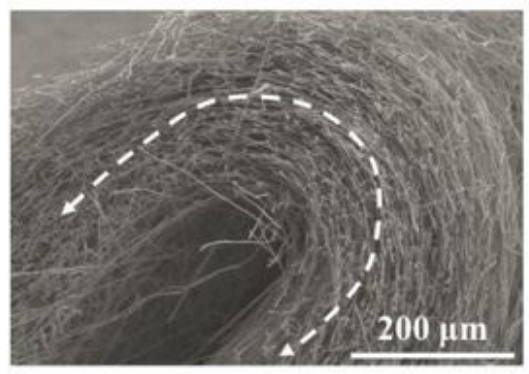

(d)

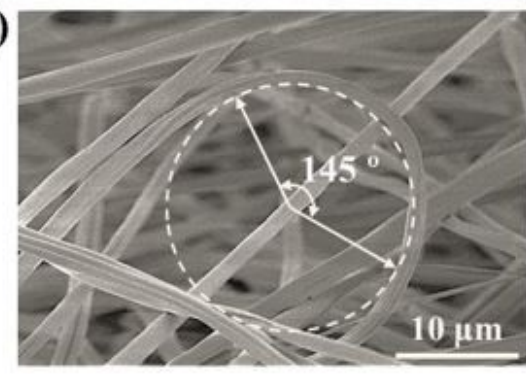

(e)

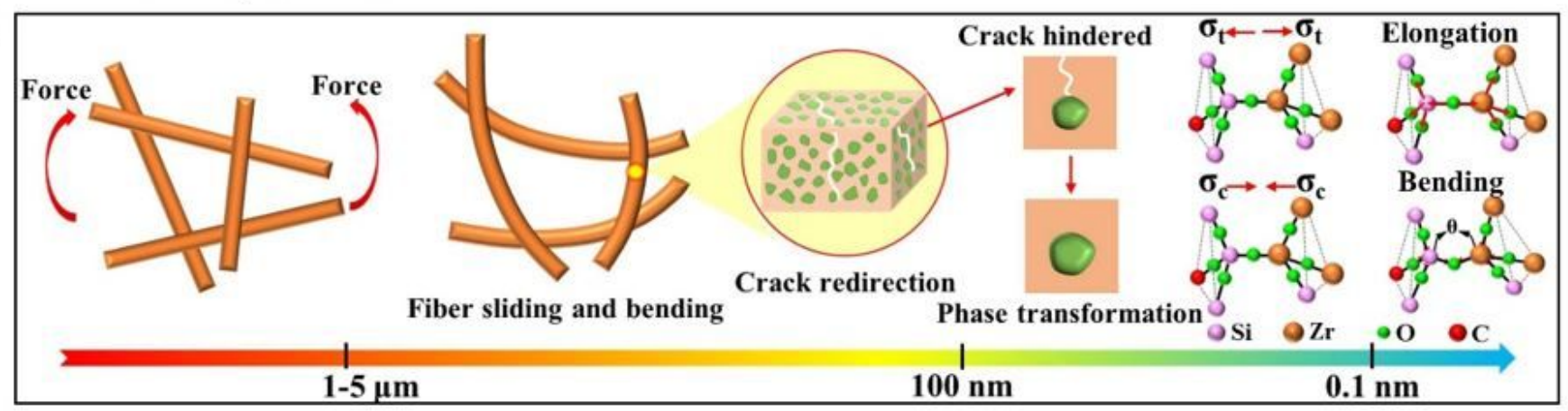

Figure 4

(a) High flexibility demonstrated by bending, twisting, knotting and rolling test of a piece of MSUFs membrane; (b) Tensile strength retention versus 100 cycles bending, twisting and rolling tests; (c) SEM image of the bent MSUF membrane; (d) SEM image showing the bending angle of a single MSUF; (e) Schematic of the flexibility mechanism of the MSUF membranes. 
(a)

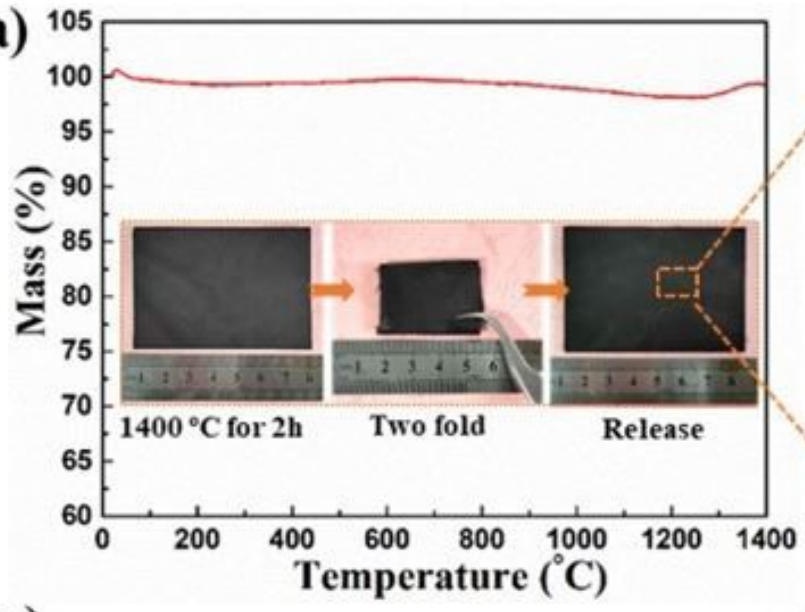

(c)

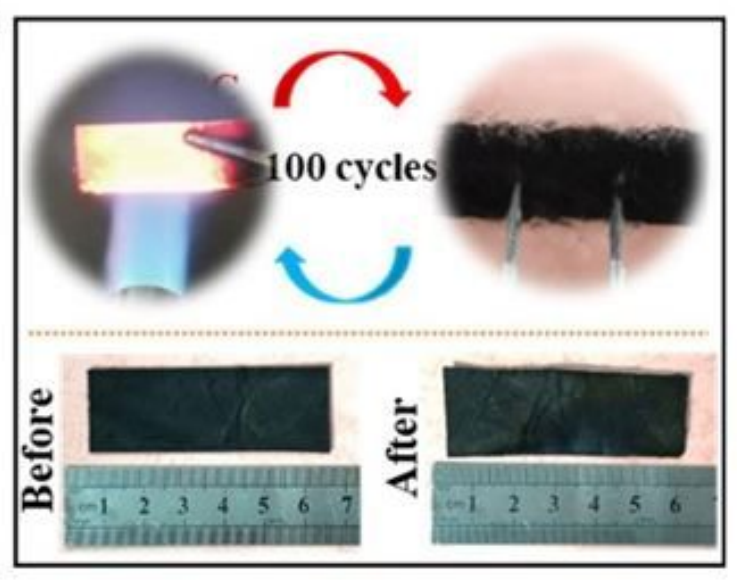

(b)

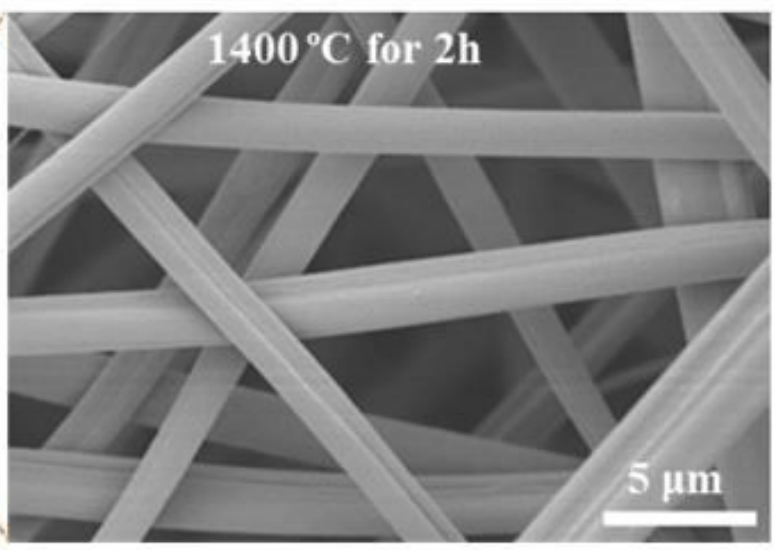

(d)

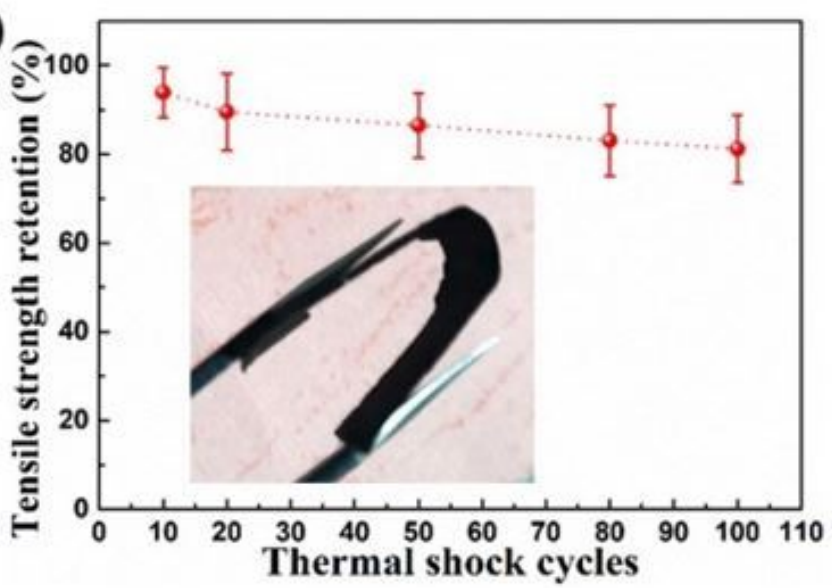

Figure 5

(a) TG curve of the MSUFs in Ar atmosphere from 25 to $1400^{\circ} \mathrm{C}$ and macroscopic images of MSUF membranes after heat treated at $1400^{\circ} \mathrm{C}$ for $2 \mathrm{~h}$ (Inset); (b) SEM image of the MSUF membranes after heat treated at $1400{ }^{\circ} \mathrm{C}$ for $2 \mathrm{~h}$; (c) Schematic of rapid thermal shock test for 100 cycles and optical photographs of MSUF membranes before and after 100 cycles thermal shock tested; (d) Tensile strength retention of MSUF membranes versus thermal shock cycles and optical photographs show high flexibility of the MSUF membranes after tested (Inset). 
(a)

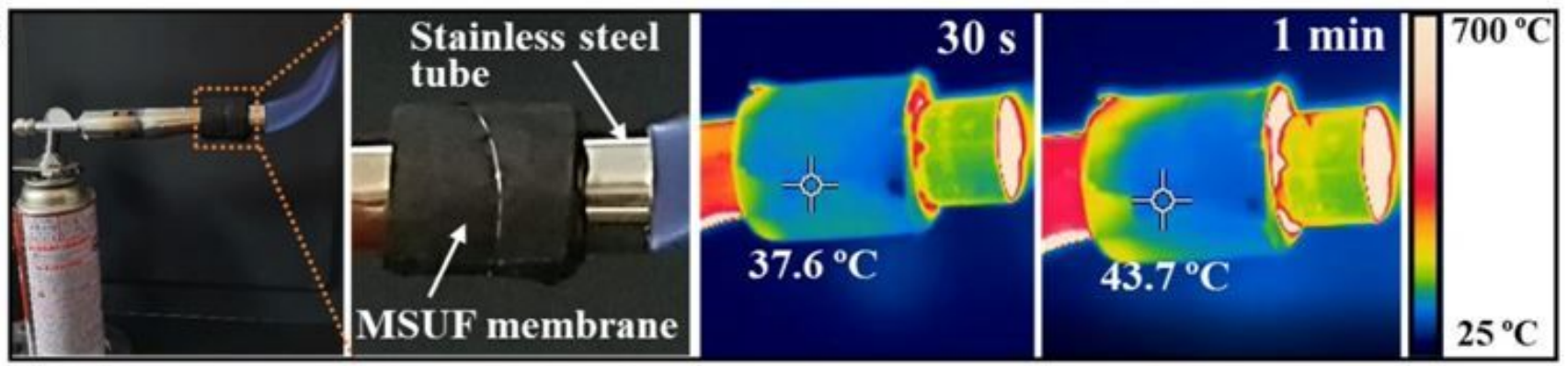

(b)

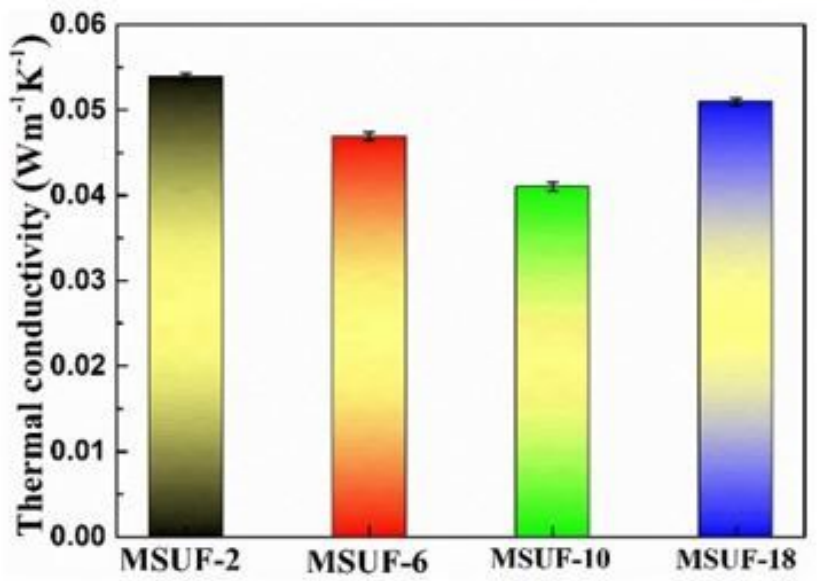

(c)

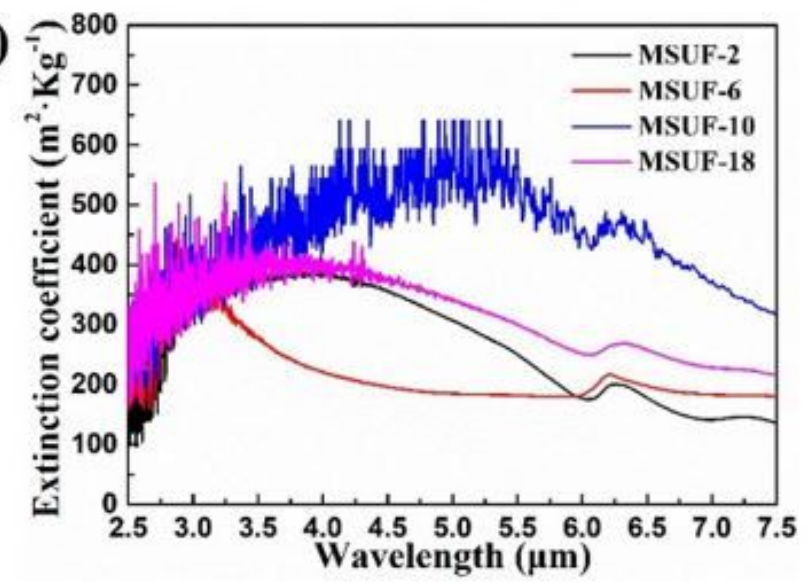

(d)

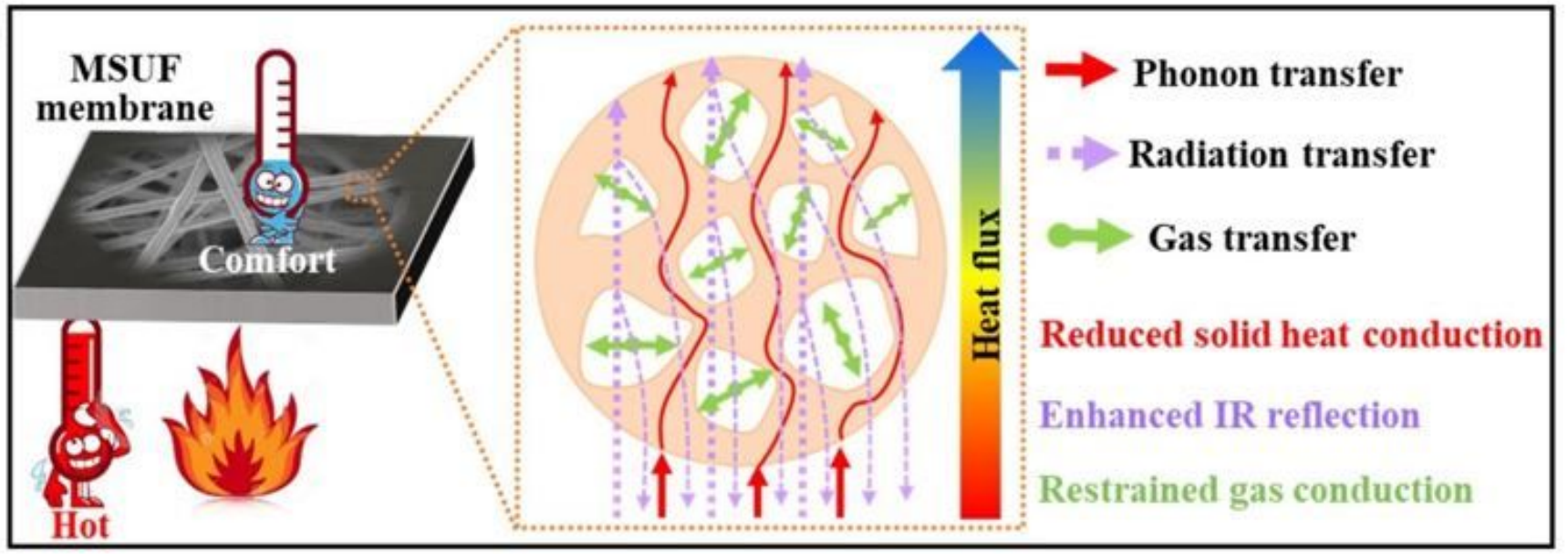

Figure 6

(a) Photo and IR images of MSUF membrane wrap around the nozzle of a butane torch; (b) Thermal conductivity of various MSUF membranes at ambient temperature; (c) $\mathrm{e}^{\star}$ versus IR wavelength from 2.5-7 $\mu \mathrm{m}$; (d) Thermal insulation mechanisms of MSUF membranes. 


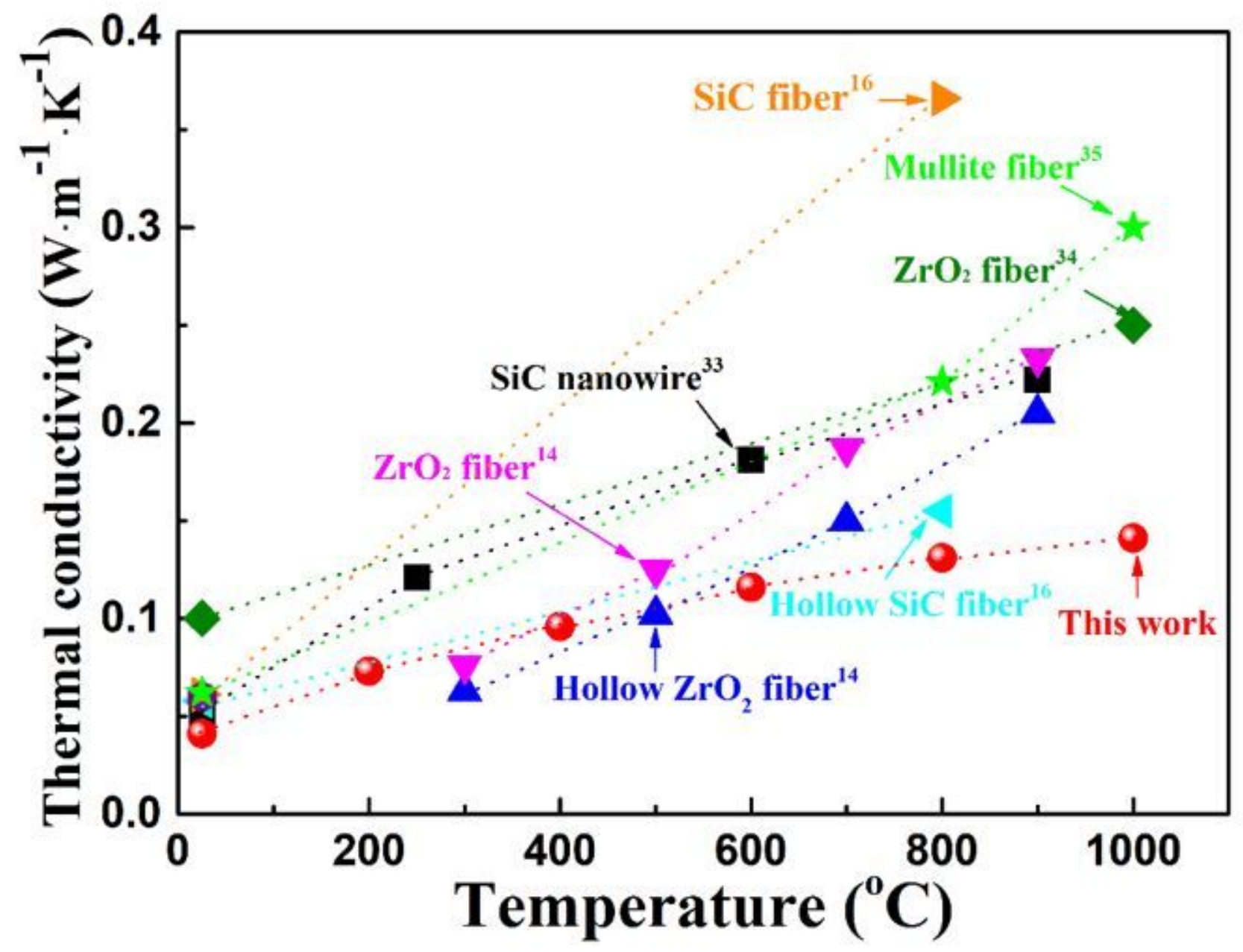

Figure 7

Thermal conductivity versus temperature of ceramic fiber membranes.

\section{Supplementary Files}

This is a list of supplementary files associated with this preprint. Click to download.

- SupplementaryMaterial.docx 